\title{
Approaches to Improve Endometrial Receptivity in Case of Repeated Implantation Failures
}

\author{
Antonis Makrigiannakis*, Fanourios Makrygiannakis and Thomas Vrekoussis \\ Department of Obstetrics and Gynecology, Medical School, University of Crete, Heraklion, Greece
}

Repeated implantation failures are a constant challenge in reproductive medicine with a significant impact both on health providers and on infertile couples. Several approaches have been proposed so far as effective; however, accumulative data have clarified that most of the treatment options do not have the evidence base for a generalized application to be suggested by the relevant societies. Implantation failures are attributed to either poor quality embryos or to defected endometrial receptivity. The current review aims to summarize in a systematic way all the new trends in managing RIF via interference with endometrial receptivity. The authors focus mainly, but not exclusively, on endometrial injury prior to embryo transfer and endometrial priming with autologous cells or biological agents. To this direction, a systematic search of the Pubmed database has been conducted taking into account the emerged evidence of the last two decades. All the suggested interventions are herein presented and analyzed in terms of reproductive outcomes. It is evident that properly powered and designed randomized trials are needed to support a new standard approach in RIF treatment that will safely be incorporated in national and international guidelines.

Keywords: repeated implantation failures, HCG, PBMC, PRP, microbiome, G-CSF, atosiban, growth hormone

${ }^{*}$ Correspondence:

Antonis Makrigiannakis amakrigiannakis@gmail.com; makrygia@uoc.gr

\section{INTRODUCTION}

Repeated implantation failure (RIF) is one of the main challenges in human reproduction. Due to the fact that RIF was initially considered a rather heterogeneous entity, a definition was difficult to establish. It is however accepted that RIF is defined as "the failure to achieve a clinical pregnancy after transfer of at least four good-quality embryos in a minimum of three fresh or frozen cycles in a woman under the age of 40 years" (Coughlan et al., 2014a). This definition is further challenged upon the number and the type of embryos transferred (number of cleavage embryos vs. number of blastocysts), along with the definition of the primary endpoint for a cycle to be successful (biochemical vs. clinical pregnancy) (Cakiroglu and Tiras, 2020). Even so, the even existence of RIF as a clinical entity is under doubt (Ben Rafael, 2020). Due to the diversity of the RIF definitions, data on RIF incidence is rather restricted (Bashiri et al., 2018).

RIF is a burden both for the health providers and the couples. Health providers are required to proceed to assisted reproduction techniques with rather small success rates, while the couples are overloaded with psychological stress (Coughlan et al., 2014b; Stanhiser and Steiner, 2018), not to mention the financial pressure due to the repeated cycles. It is thus imperative for health providers to employ novel tools aiming to improve the reproductive outcome. So far, only hysteroscopy to treat endometrial pathology (Mao et al., 2019), and treatment of hydrosalpinges (Coughlan, 2018) 
have been proven significantly beneficial and as such they have been incorporated in standard care. However, several approaches have emerged in the literature claiming to act like the "Holy Grail” in management of unexplained RIF.

Herein, we present a systematic effort to present the existing evidence on most of the novel approaches aiming to improve implantation and thus reproductive outcomes in case of unexplained RIF.

\section{THE ENDOMETRIAL PATHOPHYSIOLOGY OF RIF}

The etiology of RIF can be attributed to dysfunction of the two major players of implantation, namely the embryo and the endometrium. As far as the embryo is concerned, poor quality embryos or sperm along with parental chromosomal anomalies are the main causes of an embryo failing to implant (Coughlan et al., 2014a). Such issues of poor quality gametes can be easily diagnosed prior to IVF. On the other hand, deranged endometrial receptivity is more difficult to evaluate; apart from hysteroscopy to assess the endometrial cavity, only very recently molecular diagnostic arrays have been available in order to predict an IVF candidate as a RIF patient; however, the evidence is rather weak for such approach to be established in clinical practice (Bassil et al., 2018). The molecular signature of RIF is constantly under investigation; a recent report has shown that a molecular signature of 303 genes extracted from endometrial sampling could safely discriminate between normal and RIF individuals (Koot et al., 2016). Such approaches, although promising, need further validation in order to be released for clinical practice.

\section{The Endometrial Pathophysiology of RIF: Well-Established RIF Causes}

\section{Anatomical Disorders}

RIF may be attributed to anatomical disorders that distort the endometrial cavity, being undiagnosed before IVF treatment. In that context, fibroids have been reported as negative prognosticators to IVF success (Wang et al., 2018; Rikhraj et al., 2020), altering endometrial receptivity by modifying HOXA10 and LIF expression (Makker et al., 2017; Kara et al., 2019; Pier et al., 2020). Endometrial adhesions as a result of infection or prior surgical procedure may also be considered to be associated with thin endometrium and low receptivity potential (Wang et al., 2020). Finally, hydrosalpinges are well-accepted as a cause for RIF, since the inflammatory fluid may affect both the embryo and the endometrium (Volodarsky-Perel et al., 2019). Of note is the fact that patients with the above mentioned anatomical disorders may receive surgical treatment prior to IVF with significantly improved reproductive outcomes.

\section{Unexplained RIF: Proposed Endometrial Pathophysiology Immunological Disorders}

The immunological profile of the receptive endometrium presents several characteristics that seem to be impaired in case of implantation failure. The first cellular population to be considered of interest was the natural killer (NK) cells, due to their ability to destroy allogenic cellular signals. It has been previously reported that increased numbers and activity of peripheral NK cells are associated with a negative pregnancy outcome (biochemical pregnancy or miscarriage) (Yamada et al., 2003). To the same direction, a parallel increase in peripheral and uterine NK cell numbers and NK activity was found in women diagnosed as RIF (Santillán et al., 2015). However, the role of the NK cells in human reproduction is quite complex; NK cells constitute a rather diverse cellular population making the discrimination between peripheral and uterine NK cells rather difficult. Interestingly, it was shown that even uterine NK cells may be divided into three subsets with different immunological properties (Vento-Tormo et al., 2018). Perhaps, due to this diversity, the first meta-analysis in the field, including studies assessing NK cell biology prior IVF treatment, showed no significant difference in NK cell count and activity between fertile and infertile women (Seshadri and Sunkara, 2014). Emerging evidence now put in doubt the initial notion that NK cell density and activity may predict RIF (Donoghue et al., 2019; Zhang et al., 2020), while a recent meta-analysis highlights that studies reporting interventions based on NK status are heterogeneous and lack the quality to produce solid evidence (Woon et al., 2020).

The role of differential expression of several cytokines in implantation has been well described in the literature. A constant shift to a Th1 cytokine pro-inflammatory profile contributes to implantation failure or miscarriage (Liang et al., 2015). On the contrary, a shift toward a Th2 anti-inflammatory cytokine profile supports implantation and early fetal development. Interestingly, a successful implantation requires a T-regulatory (Treg) cell profile, while a shift toward a Th17 phenotype is associated with poor reproductive outcomes (Ali et al., 2018). It is reported that up to $80 \%$ of RIF cases may present with an abnormal cytokine profile (Lédée et al., 2016). It must be pointed out though, that, even well-studied, the above mentioned findings should be met with caution. The correlation of the immune profile with reproductive success has not been principally validated; it has been proven within special research settings.

\section{Non-immunological Disorders}

Several signaling pathways have been reported as impaired in case of repeated implantation failures. A recent transcriptome analysis has revealed that, in case of RIF, leukemia inhibitory factor (LIF) was reduced along with the expression of S100 calcium binding protein $\mathrm{P}$ (S100P), Chemokine (C-X-C motif) ligand 13 (CXCL13), SIX homeobox 1 (SIX1) and signal transducer, and activator of transcription 3 (STAT3) (Choi et al., 2016). Additionally, the endometrium of RIF patients has been characterized as of low MUC1 expression, this being an independent prognosticator of implantation failure ( $\mathrm{Wu}$ et al., 2018). Furthermore, platelet and endothelial cell adhesion molecule 1 (PECAM1) and transforming growth factor $\beta 1$ (TGF$\beta 1$ ) were also significantly reduced in RIF (Guo et al., 2018). Apart from altered implantation markers, it has been previously shown that prostaglandins' synthesis is deranged in case of RIF, implying 
a defective endometrial inflammation in favor of implantation failure (Achache et al., 2010; Demiral Keleş et al., 2020). Finally studies evaluating metabolomics (RoyChoudhury et al., 2016) and microRNAs (Shi et al., 2017) have shown that RIF may be featured by a significant different profile that could be associated with poor reproductive outcome.

\section{Chronic Endometritis}

Chronic endometritis (CE) is an emerging entity considered to negative affect reproductive outcomes in case of IVF treatment. Especially in RIF, CE has been reported at an incidence of ranging from 14 to $30 \%$ with decreased pregnancy success rates (Quaas and Dokras, 2008; Bouet et al., 2016). EC diagnosis is rather complicated. Endometrial cavity assessment is initially performed via hysteroscopy, recognizing subtle endometrial lesions like micropolyps, stromal edema and profound vascularity attributed to inflammatory angiogenesis (Gkrozou et al., 2020). The gold standard in establishing CE diagnosis is the recognition of increased plasma cell density in the endometrial stroma, either by standard histology (Kasius et al., 2012), or even better, by immunohistochemically marking plasma cells with anti-CD163 (Fan et al., 2019; Li et al., 2020; Xu et al., 2020). A complementary approach is endometrial sampling for microbial culture. The most common pathogens identified are so far group B Streptococcus, Escherichia Coli, Streptococcus Faecalis, Mycoplasma (Cicinelli et al., 2015). Of note is the constant risk of sample contamination with vaginal or cervical pathogens. CE is considered to affect endometrial receptivity via establishing a dysbiotic endometrial environment featured by dense lymphocyte populations along with a shift toward inflammatory cytokine profiles (Th1/Th17) (Mor and Kwon, 2015; Al-Nasiry et al., 2020).

\section{Thin Endometrium}

Although there is no universal consensus about the threshold of thin endometrium, an endometrial thickness below $8 \mathrm{~mm}$ is generally accepted as characteristic for thin endometrium. Thin endometrium is a risk factor for implantation failure (Liu et al., 2018). Thin endometrium could be initially attributed to previous endometrial infection or intra-cavitary intervention. In the absence of an obvious cause, it is suggested that it could be the end result of defective angiogenesis, depriving the endometrium from the necessary nutrients and oxygen (Miwa et al., 2009). Several approaches have been proposed including adhesiolysis and estrogen treatment (Lebovitz and Orvieto, 2014). However, thin endometrium remains a challenge and as such novel approaches need to be devised and properly evaluated.

\section{Dysbiotic Microbiome: A Novel Pathophysiologic Approach in RIF}

During the last decade, with the technological evolution of new generation sequencing, it became feasible to evaluate the microbiome of the reproductive system. It is currently known that the vagina microbiome is considered of low diversity, having predominantly lactobacillus species (Ravel et al., 2011). Lactobacillus is the natural guardian of the vagina, since it metabolizes glycogen released by vaginal epithelium to lactic acid, securing a low $\mathrm{pH}$ which in turn inhibits the growth of local pathogens. Several controlled studies have been published, demonstrating that altered vaginal or even endometrial microbiome could be associated with poor reproductive outcomes. Of note is the study by Moreno et al. (2016) showing that pathological endometrial microbiota are associated with implantation failure. These studies have been recently systematically reviewed with the conclusion being supportive for the altered lactobacillus population to be a potential cause of impaired endometrial receptivity (BracewellMilnes et al., 2018). Normal endometrial microbiome is expected to be of low biomass, exerting a moderate local immune stimulation in favor of normal tissue remodeling (Einenkel et al., 2019). Furthermore, it is expected to support the endometrium via production of metabolites, while concurrently it blocks pathogen migration via spatial antagonization (Benner et al., 2018). On the contrary, dysbiotic microbiota are featured by abundancy and a powerful immune stimulation with a local destructive result (Einenkel et al., 2019). It has been noted that normally, the endometrial microbiome contributes to a cytokine profile toward Th2/Treg immunity (Al-Nasiry et al., 2020). On the other hand, dysbiosis, induces a Th1/Th17 profile exerting a negative effect on tissue remodeling and trophoblast invasion (Al-Nasiry et al., 2020). Finally, the dysbiotic microbiome contributes to local oxidative stress with detrimental effect on endometrial cell homeostasis (Baker et al., 2018).

Despite the initiated enthusiasm, there are several issues regarding the procedure of sampling and evaluating endometrial microbiota. It has been reported that endometrial microbiome may fluctuate according to the circulating estrogen and progesterone (Molina et al., 2020). Additionally, it may be altered by infectious agents, increasing age, physical activity, pregnancy and childbirth (Molina et al., 2020). More importantly, endometrial microbiome evaluation is under the influence of technical details that need standardization. There is always the risk of contamination by the vaginal microbiome (Salter et al., 2014; Glassing et al., 2016). This demands a careful sampling along with setting proper negative controls (Kim et al., 2017). The platform used for sequencing may also affect the results (Clooney et al., 2016). Moreover, since endometrial microbiome is of low biomass, special DNA isolation kits are needed in order to minimize the risk of misinterpretation of the results along with the risk of inserting bias via the statistical method applied (Eisenhofer et al., 2019; Weyrich et al., 2019). Finally, the results need further critical analysis, since detecting 16s rRNA does not mean that the strains identified are necessary viable or abundant. To this direction, no "core endometrial microbiome" has been presented so far, nor has this been correlated with normal/fertile endometrium or any uterine pathology (like polyps or retarded decidualization).

\section{MATERIALS AND METHODS}

The aim of the current study was to highlight novel approaches in the field of unexplained RIF treatment. The Pubmed database was screened with the following searches: ("Endometrial injury" 
OR "Endometrial scratching”), [("HCG” OR "human chorionic gonadotropin") AND ("intrauterine" OR “infusion” OR "injection" OR "administration")], [(“PBMC" OR "peripheral blood mononuclear cells" OR "peripheral blood monocytes") AND ("intrauterine" OR "infusion" OR "injection" OR "administration")], [(“G-CSF" OR "Granulocyte colony stimulating factor") AND ("IVF" OR “assisted reproduction")], [("atosiban" AND ("IVF” OR “assisted reproduction”)], [("GH" OR "Growth hormone") AND ("IVF" OR "assisted reproduction")], [("PRP” OR "platelet-rich plasma") AND ("IVF" OR “assisted reproduction")], ("antibiotics" AND "chronic endometritis"), [("microbiome" AND ("IVF" OR "assisted reproduction")]. The publications were screened by title relevance and thereafter by abstract relevance. Only controlled trials and meta-analyses were included. Meta-analyses' references were also screened for Pubmed publications.

\section{APPROACHES TO IMPROVE ENDOMETRIAL RECEPTIVITY IN UNEXPLAINED RIF PATIENTS}

\section{The Role of Endometrial Injury in Improving Reproductive Outcomes in Women With RIF}

The concept of performing an endometrial injury as a means of improving endometrial receptivity has been reported by Barash et al. (2003). The authors demonstrated, for the first time, a significant improvement both in implantation and clinical pregnancy rates. This report triggered a massive positive reaction by clinical research teams aiming to incorporate this simple and low cost approach in their everyday clinical practice. As a result, both basic science teams and clinicians published a significant number of studies in the view both to delineate possible potential pathophysiological mechanisms, along with producing solid clinical evidence for endometrial injury to be accepted as a therapeutic procedure.

As far as basic science is concerned, endometrial injury has initially been proposed to induce an aseptic inflammatory reaction possibly shifting the endometrial immune profile toward a Th2/M2 state (Granot et al., 2012). It was, thus, shown that endometrial injury may up-regulate the endometrial expression of several pro-decidualization molecules, including MUC-1, crystalline aB, APOD, and PLA2 (Kalma et al., 2009). MUC-1 is known to be up-regulated by progesterone affecting endometrial receptivity, acting at the same time as an independent receptivity marker in case of RIF (Wu et al., 2018). To the same direction, it has been shown that endometrial injury may induce uroplakin Ib expression, a molecule up-regulated mainly during the window of implantation (Kalma et al., 2009). Further studies have shown an induction of the endometrial repair mechanism involving the up-regulation of TNF $\alpha$ (Gnainsky et al., 2010). This in turn initiates the chemo-attraction of monocytes and dendritic cells, thus increasing the number of endometrial macrophages in favor of the implantation process, since they trigger the endometrial expression of osteopontin, a well-known receptivity marker (Gnainsky et al., 2015). More recent studies have also highlighted the activation of local angiogenesis as this is identified by elevated expression of VEGF, a phenomenon attributed to elevated HIF-1 $\alpha$ expression as a result of inflammatory hypoxia (Yu et al., 2019). The complex network of aseptic inflammation and angiogenesis mediators has been considered as a positive contributor to receptivity (Yang et al., 2019).

In the field of clinical trials, many non-randomized and randomized controlled trials have been published (summarized in Table 1). All the trials have employed endometrial injury following various protocols in terms of: (a) number of procedures prior to embryo transfer, and (b) the timing of the procedure (follicular or luteal phase or both). Following the time line of the trials published since 2003 up to present, it can be recognized that initially the results were very supportive of the procedure and this was further presented in the first meta-analyses presented in 2012 (El-Toukhy et al., 2012; Nastri et al., 2012; Potdar et al., 2012). The initial enthusiasm was followed by comments regarding the quality of the included randomized trials, along with concerns upon a possible selection bias (Simón and Bellver, 2014). Since then, further studies of different sizes and methodology have been added, increasing the heterogeneity. Due to the lack of uniformity in performing the procedure, the most recent meta-analyses have noted the weaknesses of the randomized trials, pooling data that lead to rather discouragement (Gui et al., 2019; Sar-Shalom Nahshon et al., 2019; van Hoogenhuijze et al., 2019; Vitagliano et al., 2019). To this direction, a critical review of the randomized controlled trials published so far, revealed several issues in trials' design, underlying that caution is needed especially when pooling low-quality evidence (Li et al., 2019). Very recently, a properly powered randomized trial has been published (Lensen et al., 2019a). Having recruited 1,364 patients randomized to receive or not an endometrial injury prior to embryo transfer, the authors state that performing an endometrial injury in everyday practice does not significantly alter the reproductive outcomes (Lensen et al., 2019a).

The evidence produced from this study (Lensen et al., 2019a), has initiated a long series of debates in terms of the endometrial injury application, along with the ethical dilemma of offering a procedure proven as useless or even possibly harmful (Yeung et al., 2014; Frantz et al., 2019; Lensen et al., 2019b; Mackens et al., 2020). This is especially important in case of selected groups receiving assisted reproduction treatments like women with RIF. Although Lensen et al. reported that endometrial injury was not efficient in women with RIF (Lensen et al., 2019a), this result was extracted by a sub-group analysis of the population. Despite the fact that the study was properly powered to identify a significant difference of $15 \%$ between the study and the control groups, there are always methodological issues in sub-group analyses, mainly due to lack of stratified randomization (VanderWeele and Knol, 2011; Lensen et al., 2019b). The clinical evidence to support endometrial injury in women with RIF is based on significantly fewer studies compared to the total number of studies published so far (see Table 1). The heterogeneity of these studies was addressed in a previous systematic review (Panagiotopoulou et al., 2015). Most of the studies have been summarized in a recent meta-analysis which clearly demonstrates that in case of 
TABLE 1 | Salient features of the included studies on endometrial injury as an intervention in improving endometrial receptivity.

\begin{tabular}{|c|c|c|c|c|c|}
\hline Year & PMID & Publication type & Participants & RIF & Outcome \\
\hline 2020 & 32468267 & $\mathrm{RCT}$ & 352 & Not exclusively & Non-significant \\
\hline 2020 & 32372078 & $\mathrm{RCT}$ & 200 & Not exclusively & Negative-premature end \\
\hline 2020 & 32216503 & Non-randomized & 518 & Not exclusively & Significant \\
\hline 2020 & 32003122 & $\mathrm{RCT}$ & 200 & YES & Significant \\
\hline 2020 & 31897673 & Non-randomized & 300 & Not exclusively & Significant in RIF \\
\hline 2019 & 31843072 & $\mathrm{RCT}$ & 304 & Not exclusively & Significant in RIF \\
\hline 2019 & 31532321 & Non-randomized & 62 & YES & Significant in RIF \\
\hline 2019 & 31450870 & Non-randomized & 137 & Not exclusively & Non-significant \\
\hline 2019 & 31405721 & $\mathrm{RCT}$ & 239 & YES & Significant in RIF \\
\hline 2019 & 30895265 & Meta-analysis & 2537 & Not exclusively & Non-significant \\
\hline 2019 & 30683590 & Meta-analysis & 1354 & Not exclusively & Non-significant \\
\hline 2019 & 30673547 & $\mathrm{RCT}$ & 1364 & Not exclusively & Non-significant \\
\hline 2019 & 30661093 & $\mathrm{RCT}$ & 51 & Not exclusively & Non-significant-premature end \\
\hline 2019 & 30515920 & Non-randomized & 266 & Not exclusively & Significant \\
\hline 2019 & 30421580 & Meta-analysis & 4057 & Not exclusively & Non-Significant in RCTs Significant overall \\
\hline 2019 & 30388238 & Meta-analysis & 1260 & Not exclusively & Non-significant \\
\hline 2019 & 30496529 & $\mathrm{RCT}$ & 191 & Not exclusively & Non-significant-Premature end \\
\hline 2018 & 29048754 & $\mathrm{RCT}$ & 300 & Not exclusively & Significant \\
\hline 2018 & 30196966 & Meta-analysis & 1468 & YES & Significant in RIF \\
\hline 2017 & 29259469 & $\mathrm{RCT}$ & 77 & YES & Significant in RIF \\
\hline 2017 & 28964963 & $\mathrm{RCT}$ & 80 & Not exclusively & Non-significant \\
\hline 2017 & 28551840 & $\mathrm{RCT}$ & 144 & Not exclusively & Significant \\
\hline 2017 & 28511086 & $\mathrm{RCT}$ & 111 & Not exclusively & Non-significant \\
\hline 2017 & 28447502 & Non-randomized & 576 & Not exclusively & Non-significant \\
\hline 2017 & 28397981 & $\mathrm{RCT}$ & 106 & Not exclusively & Significant \\
\hline 2017 & 28386815 & Non-randomized & 429 & YES & Significant in RIF \\
\hline 2017 & 28612975 & $\mathrm{RCT}$ & 169 & Not exclusively & Non-significant \\
\hline 2016 & 28101111 & $\mathrm{RCT}$ & 120 & YES & Non-Significant in RIF \\
\hline 2016 & 27910711 & Non-randomized & 103 & YES & Significant in RIF \\
\hline 2016 & 27363928 & $\mathrm{RCT}$ & 120 & Not exclusively & Non-significant \\
\hline 2016 & 27738660 & $\mathrm{RCT}$ & 63 & Not exclusively & Negative \\
\hline 2016 & 27525329 & $\mathrm{RCT}$ & 93 & Not exclusively & Non-significant \\
\hline 2016 & 27296541 & Meta-analysis & 1512 & Not exclusively & Uncertainty due to low quality \\
\hline 2016 & 27294218 & $\mathrm{RCT}$ & 400 & Not exclusively & Significant \\
\hline 2016 & 27258405 & Non-randomized & 345 & YES & Significant in RIF \\
\hline 2016 & 27146582 & $\mathrm{RCT}$ & 360 & Not exclusively & Significant \\
\hline 2016 & 26342054 & RCT & 154 & Not exclusively & Significant \\
\hline 2015 & 26752857 & RCT & 60 & YES & Significant implantation rate \\
\hline 2015 & 26538858 & $\mathrm{RCT}$ & 251 & Not exclusively & Significant \\
\hline 2015 & 25803542 & Meta-analysis & 2128 & Not exclusively & Significant \\
\hline 2015 & 25561347 & $\mathrm{RCT}$ & 387 & Not exclusively & Significant only in RIF \\
\hline 2015 & 26344351 & $\mathrm{RCT}$ & 332 & Not exclusively & Non-significant \\
\hline 2014 & 25469138 & $\mathrm{RCT}$ & 144 & Not exclusively & Non-significant \\
\hline 2014 & 25205759 & $\mathrm{RCT}$ & 300 & Not exclusively & Non-significant \\
\hline 2014 & 25064410 & Non-randomized & 737 & Not exclusively & Non-significant in RIF \\
\hline 2014 & 24791967 & Non-Randomized & 80 & Not exclusively & Non-significant \\
\hline 2014 & 24289893 & Non-randomized & 118 & Not exclusively & Significant \\
\hline 2013 & 24639710 & RCT & 217 & Not exclusively & Significant \\
\hline 2013 & 23754314 & $\mathrm{RCT}$ & 158 & Not exclusively & Significant \\
\hline 2013 & 23106834 & RCT & 101 & Not exclusively & Significant \\
\hline 2013 & 23494199 & $\mathrm{RCT}$ & 150 & Not exclusively & Significant \\
\hline 2013 & 24283157 & Non-randomized & 89 & YES & Significant in RIF \\
\hline 2012 & 25246928 & Non-randomized & 83 & Not exclusively & Significant \\
\hline
\end{tabular}


TABLE 1 | Continued

\begin{tabular}{|c|c|c|c|c|c|}
\hline Year & PMID & Publication type & Participants & RIF & Outcome \\
\hline 2012 & 23063812 & Meta-analysis & 2062 & YES & Significant in RIF \\
\hline 2012 & 22885017 & Meta-analysis & 901 & Not exclusively & Significant \\
\hline 2012 & 22943664 & RCT & 36 & YES & Negative in RIF \\
\hline 2012 & 22835632 & $\mathrm{RCT}$ & 200 & YES & Significant in RIF \\
\hline 2011 & 22014336 & Non-randomized & 30 & Not exclusively & Significant \\
\hline 2011 & 26396577 & Non-Randomized & 74 & Not exclusively & Non-Significant \\
\hline 2010 & 20607003 & $\mathrm{RCT}$ & 100 & Not exclusively & Significant \\
\hline 2010 & 19568761 & RCT & 77 & Not exclusively & Negative \\
\hline 2009 & 20070722 & $\mathrm{RCT}$ & 115 & YES & Significant in RIF \\
\hline 2008 & 17681303 & RCT & 121 & Not exclusively & Significant \\
\hline 2007 & 17197286 & Non-randomized & 117 & YES & Significant in RIF \\
\hline 2003 & 12798877 & Non-randomized & 134 & Not exclusively & Significant \\
\hline
\end{tabular}

women with RIF, endometrial injury may significantly improve reproductive outcomes (Vitagliano et al., 2018a). Interestingly, the same research group has demonstrated in a separate metaanalysis that the positive effect of the procedure does not exist in case of women receiving their first IVF treatment (Vitagliano et al., 2019). This is in line with the report of Lensen et al. (2019a), strengthening the notion that endometrial injury should not be an everyday practice anymore. A properly designed randomized controlled trial is expected to delineate whether offering endometrial injury is beneficial to women with RIF. Until then, the patients should be properly informed about the potential benefits of the procedure and the lack of solid evidence.

\section{Intrauterine Administration of Human Chorionic Gonadotropin (HCG)}

The concept of administering HCG in the uterine cavity before embryo transfer was based on evidence produced during the last two decades. It is well-established that HCG is the first molecule to participate in the cross-talk between the embryo and the maternal decidua. HCG is expressed even at the stage of the 8-cell embryos (Bonduelle et al., 1988; Lopata and Hay, 1989), following a specific pattern of augmentation during implantation and trophoblast invasion, inducing the differentiation of the cytotrophoblast to syncytiotrophoblast. At the same time a switch from the standard HCG to the hyperglycosylated HCG isoform (H-HCG) is characteristic during blastocyst hatching, with the latter being involved in extravillous trophoblast proliferation and invasion (Cole, 2010; Guibourdenche et al., 2010). It is thus evident that the concurrent actions of HCG and HCG-H enhance placentation and thus early fetal development.

The role of HCG was further established in reproductive physiology by several reports investigating the impact of HCG on the endometrium during decidualization, implantation and trophoblast invasion. HCG was found to induce $\alpha$-smooth muscle actin in endometrial stroma fibroblasts (Fazleabas et al., 1999), a fact linked to decidualization. Additionally, HCG was reported to be a regulator of glycodelin (Toth et al., 2008) and progesterone receptors' expression (Tapia-Pizarro et al., 2017), both regulating decidualization. To the same direction HCG was demonstrated as a facilitator of implantation, since several receptivity-related molecules like VEGF, HOXA-10, and galectin-3 are up-regulated by HCG (Fogle et al., 2010; Yang et al., 2013). Interestingly, HCG was recently reported to mediate chemo-attraction (Schumacher et al., 2009) and differentiation of T-regulatory (Treg) cells (Diao et al., 2017), while inducing T-cell apoptosis via the Fas/FasL system, thus acting as a local immunomodulator during implantation and trophoblast invasion (Kayisli et al., 2003). Concurrently, HCG was shown to promote trophoblast invasion by upregulating the pro-invasive VEGF, LIF and MMP-9 (Licht et al., 1998; Fluhr et al., 2008a,b), while downregulating tissue inhibitors of metalloproteinases (Fluhr et al., 2008a; Tapia-Pizarro et al., 2013). Interestingly, HCG may also pose a negative effect on the endometrium; a prolonged lowdose HCG administration was proved to downregulate the LHHCG receptor, possibly making the endometrium unresponsive to blastocyst secreted HCG (Evans and Salamonsen, 2013).

All the above established an evidence base for clinical trials. A moderate number of clinical trials have been performed so far (summarized in Table 2), with the majority of them being randomized controlled trials (Mansour et al., 2011; Hong et al., 2014; Santibañez et al., 2014; Zarei et al., 2014; Aaleyasin et al., 2015; Wirleitner et al., 2015; Dehghani Firouzabadi et al., 2016; Navali et al., 2016; Huang et al., 2017a; Mostajeran et al., 2017; Boonsuk et al., 2018; Hafezi et al., 2018; Laokirkkiat and Thanaboonyawat, 2019). Despite the anticipation for solid evidence, an in-depth evaluation reveals high heterogeneity due to different methodologies applied. Indeed, treatment protocols differ in terms of HCG dosage, timing of intrauterine administration and the stage of the embryos transferred. Apart from protocol heterogeneity, patient characteristics differ as well, ranging from infertile women to patients experiencing repeated implantation failures. These differences can initially explain the contradicting results of the published trials along with the opposing conclusions drawn by the meta-analyses performed during the last 5 years. So far four meta-analyses (Ye et al., 2015; Osman et al., 2016; Hou et al., 2018; Gao et al., 2019) and one Cochrane review (Craciunas et al., 2018) have been performed with opposing results. Only 2 out of the 4 meta-analyses present a significant benefit (Ye et al., 2015; Gao et al., 2019). An in-depth analysis of the most recent meta-analyses has revealed differences in the included studies, mainly being reports published as 
TABLE 2 | Salient features of the included studies on HCG as an intervention in improving endometrial receptivity.

\begin{tabular}{|c|c|c|c|c|c|}
\hline Year & PMID & Publication type & Participants & RIF & Outcome \\
\hline 2019 & 31704529 & Meta-analysis & 1,432 & YES & Significantly Favorable in RIF \\
\hline 2019 & 31277770 & Meta-analysis & 2,763 & Not exclusively & Significantly Favorable \\
\hline 2019 & 30659362 & Non-randomized & 305 & YES & Significantly favorable in RIF \\
\hline 2019 & 30449012 & RCT & 200 & Not exclusively & Significantly favorable only for implantation rates \\
\hline 2018 & 30291482 & Meta-analysis & 2,759 & Not exclusively & Non-significant \\
\hline 2018 & 30341915 & Meta-analysis & 4,751 & Not exclusively & $\begin{array}{l}\text { Significantly favorable only in case of cleavage } \\
\text { embryos and HCG } \geq 500 \mathrm{IU}\end{array}$ \\
\hline 2018 & 29626233 & $\mathrm{RCT}$ & 180 & Not exclusively & Non-significant \\
\hline 2018 & 29288552 & Non-randomized & 225 & YES & Significantly favorable for RIF \\
\hline 2018 & 28948440 & Non-randomized & 1,207 & Not exclusively & $\begin{array}{l}\text { Significantly unfavorable in FET and women without } \\
\text { RIF }\end{array}$ \\
\hline 2017 & 28400828 & $\mathrm{RCT}$ & 100 & Not exclusively & Non-significant \\
\hline 2016 & 27921090 & $\mathrm{RCT}$ & 159 & Not exclusively & Non-significant \\
\hline 2016 & 27680029 & $\mathrm{RCT}$ & 158 & Not exclusively & Significantly favorable \\
\hline 2017 & 27449969 & $\mathrm{RCT}$ & 161 & YES & $\begin{array}{l}\text { Significantly favorable compared to controls. } \\
\text { Placebo also improved the outcomes }\end{array}$ \\
\hline 2016 & 27317131 & Meta-analysis & 3,087 & Not exclusively & Non-significant \\
\hline 2015 & 26359294 & Meta-analysis & 1,387 & Not exclusively & Significantly favorable \\
\hline 2015 & 26141379 & $\mathrm{RCT}$ & 1,186 & Not exclusively & Non-significant \\
\hline 2015 & 25531413 & $\mathrm{RCT}$ & 483 & Not exclusively & Significantly favorable \\
\hline 2014 & 24799855 & $\mathrm{RCT}$ & 182 & Not exclusively & Significantly favorable \\
\hline 2014 & 25234040 & $\mathrm{RCT}$ & 300 & Not exclusively & Non-significant \\
\hline 2014 & 24476536 & $\mathrm{RCT}$ & 210 & Not exclusively & Significantly favorable \\
\hline 2011 & 22047664 & $\mathrm{RCT}$ & 260 & Not exclusively & Significantly favorable \\
\hline
\end{tabular}

abstracts in proceedings' volumes possibly published with less stringent criteria in terms of a peer review process. To date, the recent Cochrane review with 4,751 participants is the largest pooled population (Craciunas et al., 2018). The authors consider that a meta-analysis to address the efficacy of intra-uterine HCG administration, is not feasible due to the heterogeneity mostly attributed to the HCG dosage and the stage of the embryo transferred (Craciunas et al., 2018). To the direction of increased heterogeneity, the source of HCG administered (recombinant vs. urinary) could also be pointed out. By performing sub-group meta-analysis, Craciunas et al. (2018) conclude that HCG may improve reproductive outcomes only in case of cleavage embryos after having primed the endometrial cavity with at least 500IU of HCG. Surprisingly, being in line with the findings of Evans and Salamonsen urging for a potential negative effect of HCG in implantation (Evans and Salamonsen, 2013), a recent nonrandomized trial reported a significantly negative outcome when HCG was administered in non-RIF patients followed by a fresh embryo transfer (Volovsky et al., 2018).

The issue of HCG administration in case of women with RIF is even more perplexed. A recent proteomic analysis of women with RIF showed a different proteomic profile compared to fertile controls even in molecules not included in commercially available receptivity assays (Bielfeld et al., 2019). Interestingly it was shown in vitro that HCG could alter the proteomic profile in terms of endocytosis, HIF signaling and chemokine production (Bielfeld et al., 2019). This proves that RIF patients constitute a distinct population not to be treated simply as "infertile." Such an approach dictates clinical trials to be designed exclusively for RIF patients. So far, only one full-paper RCT has been published addressing the issue of HCG efficacy in women with RIF, reporting HCG as significantly beneficial compared to controls; however benefit was shown even from placebo, implying an underlying endometrial injury effect (Huang et al., 2017a). The major core of evidence stems from non-randomized trials. A recent meta-analysis has summarized this evidence, supporting the use of HCG as an endometrial primer prior to embryo transfer in women with RIF (Xie et al., 2019). However, this meta-analysis has included both RCTs (including 2 RCTs published as abstracts) and non-randomized trials, a fact that poses a question upon the level of evidence produced. Further properly powered studies are needed to clarify the role of intrauterine HCG administration as a treatment option in women with RIF. Until such solid evidence emerges, the most prudent approach is to adhere to the findings of Craciunas et al. (2018). Even this is the best existing evidence so far, until properly designed randomized controlled trials verify such finding, HCG is not to be incorporated in clinical practice. It could be offered as a treatment option within the frame of a research protocol.

\section{Intra-Uterine Administration of Peripheral Blood Mononuclear Cells (PBMC)}

Early reports based on in vitro and in vivo experiments have suggested that $\mathrm{PBMC}$ may modulate endometrial receptivity by (a) inducing a Th2 cytokine profile (Hashii et al., 1998), and (b) regulating trophoblast invasion (Nakayama 
et al., 2002). Further postulations have been expressed: being a heterogeneous cell population (B- and T-lymphocytes, monocytes and macrophages) PBMC were considered ideal in mimicking the implantation process, namely an acute Th1 reaction to facilitate blastocyst adhesion followed by a Th2 modulation to achieve maternal-fetal immune tolerance and controlled blastocyst invasion (Mor et al., 2011). The first landmark study in the field was published by Yoshioka et al. (2006), showing that intrauterine administration of HCG-treated PBMCs could significantly improve reproductive outcomes in women with RIF. Since then a number of studies have been performed so far, with a moderate degree of heterogeneity. The published studies (summarized in Table 3), differ in terms of (a) population characteristics (infertile vs. exclusively RIF patients), (b) the transferred embryos (cleavage embryos vs. blastocysts, fresh vs. frozen embryos), c) the PBMC activation protocol (no-activation, activation by HCG, activation by corticotropin-releasing hormone-CRH). A critical approach in the published literature reveals the fact that although the randomized controlled trials (mainly focusing at RIF) performed (Madkour et al., 2016; Yu et al., 2016; Nobijari et al., 2019; Pourmoghadam et al., 2020b) are comparable to non-randomized trials (Yoshioka et al., 2006; Okitsu et al., 2011; Makrigiannakis et al., 2015; Li et al., 2017b; Makrigiannakis et al., 2019) in terms of quantity, the pooled number of participants is greater for the non-randomized trials. This may question the level of the overall evidence produced.

Recently, an array of meta-analyses has emerged, three referring to infertile populations in general (Maleki-Hajiagha et al., 2019; Yakin et al., 2019; Yang et al., 2020) and one referring to patients with RIF (Pourmoghadam et al., 2020a). Of the meta-analysis, evaluating the method as an intervention for infertility in general, the one that supports a significant benefit to the general infertile population (MalekiHajiagha et al., 2019) involves fewer participants than the two that draw a non-significant result (Yakin et al., 2019; Yang et al., 2020). Interestingly, subgroup analysis has revealed a significant improvement in reproductive outcomes in women with RIF (Yakin et al., 2019; Yang et al., 2020). The only metaanalysis focused on RIF, having included 1,215 participants, has concluded that intra-uterine administration of PBMC significantly improves the reproductive result in women with RIF (Pourmoghadam et al., 2020a). The results of the meta-analyses, combined, regarding the significantly positive results on RIF, imply a future role for this procedure in treating women with RIF. However, these findings should be treated with caution rather than enthusiasm. The level of evidence is rather weak and thus properly powered randomized trials are needed to enhance the evidence base to an acceptable level.

\section{Intrauterine Administration of Platelet-Rich Plasma}

Platelet-rich-plasma (PRP) is a platelet-rich whole blood extract, having removed red and white blood cells. It is considered an inexpensive means of delivering high concentrations of growth factors since activated platelets release, via their $\alpha$-granules, high concentrations of VEGF, TGF $\beta$ and PDGF (Lang et al., 2017; Baba et al., 2019). As a result PRP is considered effective as a regeneration and anti-inflammatory agent (Vitagliano et al., 2019; Arora and Arora, 2020). Local administration of PRP has been used in several medical fields like orthopedics, otolaryngology and ophthalmology. Five years ago, PRP was successfully applied for the first time as an intervention for improving refractory endometrium of women to receive IVF (Chang et al., 2015). Since then, several case series have been published with promising results. So far, three randomized controlled trials (Eftekhar et al., 2018; Nazari et al., 2020; Zamaniyan et al., 2020) along with two non-randomized controlled trials (Chang et al., 2019; Coksuer et al., 2019) have been published showing significant improvement of the reproductive outcomes. The single metaanalysis in the literature has included seven studies (625 participants) of which 3 were randomized controlled trials and four were cohort studies (Maleki-Hajiagha et al., 2020) (Table 4). One of these four studies compared PRP administration with G-CSF administration while the rest used untreated controls (Maleki-Hajiagha et al., 2020). Of the three RCTs included, one was available as abstract. It was shown that all reproductive outcomes were significantly improved in PRP-treated cases (Maleki-Hajiagha et al., 2020).

TABLE 3 | Salient features of the included studies on PBMC as an intervention in improving endometrial receptivity.

\begin{tabular}{|c|c|c|c|c|c|c|}
\hline Year & PMID & Publication type & Participants & PBMC activation & RIF & Outcome \\
\hline 2020 & 32781360 & RCT & 100 & HCG & Yes & Significantly favorable in RIF \\
\hline 2020 & 31893538 & Meta-analysis & 1215 & HCG & YES & Significantly favorable in RIF \\
\hline 2020 & 31791175 & Meta-analysis & 1173 & HCG or non-activated & Not exclusively & Significantly favorable in RIF (Sub group analysis) \\
\hline 2019 & 31322496 & $\mathrm{RCT}$ & 250 & $\mathrm{CRH}$ & Not exclusively & Significantly favorable in RIF (Sub group analysis) \\
\hline 2019 & 30739317 & Non-randomized & 26 & $\mathrm{CRH}$ & YES & Significantly favorable in RIF \\
\hline 2019 & 30684765 & Meta-analysis & 886 & HCG or non-activated & Not exclusively & Significantly favorable \\
\hline 2017 & 27915038 & Non-randomized & 633 & HCG & Not exclusively & $\begin{array}{l}\text { Significantly favorable in RIF with cleavage embryos } \\
\text { (Sub group analysis) }\end{array}$ \\
\hline 2016 & 27521928 & $\mathrm{RCT}$ & 198 & HCG & YES & Significantly favorable in RIF \\
\hline 2015 & 25652716 & Non-randomized & 45 & $\mathrm{CRH}$ & YES & Significantly favorable in RIF \\
\hline 2011 & 22035703 & Non-randomized & 253 & Non-activated & Not exclusively & Significantly favorable in RIF (Sub group analysis) \\
\hline 2006 & 17021188 & Non-randomized & 35 & HCG & YES & Significantly favorable in RIF \\
\hline
\end{tabular}


The data upon women with RIF are also rather weak. Two randomized controlled trials and one non-randomized controlled trial address the PRP treatment in women with RIF reporting significant improvement in IVF efficacy (Coksuer et al., 2019; Nazari et al., 2020; Zamaniyan et al., 2020), however the patients recruited in total do not allow extraction of definite conclusions. Thus, until evidence of properly designed randomized trials emerge, PRP should be offered within the frame of a trial.

\section{Granulocyte Colony Stimulating Factor (G-CSF)}

The role of G-CSF in reproductive physiology has been mainly studied the last two decades. G-CSF is produced by the granulosa cells during ovulation (Robert et al., 2019). It can be identified in the uterus mainly on the uterine NK cells, which play a major role during implantation both by enhancing receptivity and enabling endometrial synchronization (Sharma and Das, 2014; Robert et al., 2019). More importantly, G-CSF has been shown to regulate Th2 immunity, contributing to maternal-fetal immuno-tolerance (Moldenhauer et al., 2010).

The positive effects exerted by G-CSF on endometrial receptivity and implantation, supported the idea of using G-CSF as a local or systematic immune-modulator during IVF, and thus several observational studies and thereafter randomized and non-randomized clinical trials have emerged. Of note is the heterogeneity of the studies. Different populations selected (infertile, RIF, cases with thin endometrium), different ways of administration (intrauterine, subcutaneously), different concentrations offered and different study endpoints made it difficult to extract a solid conclusion. So far 10 randomized controlled trials have been published (Barad et al., 2014; Aleyasin et al., 2016; Davari-Tanha et al., 2016; Eftekhar et al., 2016a,b; Sarvi et al., 2017; Arefi et al., 2018; Bakirarar et al., 2018; Huang et al., 2020a; Kalem et al., 2020), with conflicting results, followed by meta-analyses in a timely manner (presented in Table 5). The six meta-analyses published present rather supportive results (Zhao et al., 2016; Kamath et al., 2017; Li et al., 2017a; Hou et al., 2018; Jiang et al., 2020; Kamath et al., 2020). However, most of the meta-analyses have included both randomized controlled trials and non-randomized trials, weakening the level of evidence. The most powered meta-analysis at the moment is a Cochrane review including 15 randomized control trials with 1,253 participants (Kamath et al., 2020). The authors have shown a weak positive impact of G-CSF in reproductive outcomes, advising caution due to low quality data and increased uncertainty. As far as RIF cases

TABLE 4 | Salient features of the included studies on PRP as an intervention in improving endometrial receptivity.

\begin{tabular}{lccccc}
\hline Year & PMID & Publication type & Participants & RIF & Outcome \\
\hline 2020 & 32363968 & RCT & 98 & Yes & Significantly favorable \\
2020 & 30714427 & RCT & 97 & Yes & Significantly favorable \\
2020 & 32006776 & Meta-analysis & 625 & No & Significantly favorable \\
2019 & 30966843 & Non-randomized & 34 & Yes Significantly favorable \\
2019 & 30653117 & Non-randomized & 64 & No & Significantly favorable \\
2018 & 30545532 & RCT & 83 & No Significantly favorable
\end{tabular}

are concerned, it was found that there could be a benefit by G-CSF administration (Kamath et al., 2020).

To the same direction most of the meta-analyses have showed a positive impact of G-CSF administration in case of RIF. Due, though, to the poor quality studies included, an increased level of uncertainty is generally noted. This uncertainty is in line with a recent randomized controlled trial showing that in case of RIF patients with normal endometrial thickness, G-CSF does not alter reproductive outcome (Kalem et al., 2020). It is thus evident that G-CSF is not to be applied as infertility intervention in the general population. Even in case of RIF the evidence does not allow G-CSF incorporation to the everyday practice. Properly powered studies are needed to clarify to which group of infertile patients would G-CSF offer some benefit.

\section{Growth Hormone (GH)}

The role of growth hormone in endometrial receptivity is still under investigation. It has been shown that $\mathrm{GH}$ receptors are expressed by endometrial epithelium, selectively during the mid-luteal phase (possibly during the window of implantation) and thereafter during decidualization (Sbracia et al., 2004). This expression pattern is similar to other molecules linked to endometrial receptivity. Additionally, it has been recently reported that $\mathrm{GH}$ may act, directly or indirectly, as an inducer for VEGF and integrin B3 expression, both involved in endometrial receptivity (Cui et al., 2019). As a result, GH has been demonstrated to be a mediator toward endometrial thickening, being rather appealing as a research intervention for women with thin endometrium (Lan et al., 2019). The evidence supporting $\mathrm{GH}$ for treating infertile women stems mainly from studies focusing on poor ovarian responders, mainly due to the parallel action that GH exerts on the ovary (Altmäe and Aghajanova, 2019; Huang et al., 2020b). So far, only one randomized trial has been published studying the GH-impact on women with RIF (Altmäe et al., 2018). The authors report that GH-treated RIF patients presented with significantly thicker endometrium and achieved significantly better reproductive outcomes compared to untreated RIF patients or women receiving their first IVF cycle (Altmäe et al., 2018). Although GH treatment seems promising, the lack of evidence does not allow its use as a standard of care.

\section{Atosiban}

Atosiban is a receptor inhibitor of oxytocin and V1a vasopressin. Based on the observation that embryo-transfer may trigger uterine contractions, which could be detrimental in embryonic apposition, the first case report of a successful pregnancy after atosiban was published in 2007 (Pierzynski et al., 2007). Since then four randomized controlled trials (Table 6) have been published (Moraloglu et al., 2010; Ng et al., 2014; He et al., 2016; Yuan et al., 2019), with the most powered reporting a non-significant effect on reproductive outcomes on the general population ( $\mathrm{Ng}$ et al., 2014). A recent metaanalysis combining six studies (1,754 participants) shows a rather weak improvement in clinical pregnancy rates but no effect on live birth rates in the general population (Huang et al., 2017b). Of note is the fact that this meta-analysis included both randomized and non-randomized trials, thus 
TABLE 5 | Salient features of the included studies on G-CSF as an intervention in improving endometrial receptivity.

\begin{tabular}{|c|c|c|c|c|c|}
\hline Year & PMID & Publication type & Participants & RIF & Outcome \\
\hline 2020 & 32862740 & $\mathrm{RCT}$ & 163 & & Significantly favorable \\
\hline 2020 & 32663652 & Meta-analysis & 1164 & Yes & Significantly favorable in RIF \\
\hline 2020 & 32198409 & RCT & 157 & Yes & Non-significant \\
\hline 2020 & 31978254 & Meta-analysis & 1253 & Not exclusively & Significantly favorable in RIF (subgroup analysis) \\
\hline 2019 & 31091064 & Non-randomized & 66 & Yes & RIF patients did not differ from patients with their 1st IVF cycle \\
\hline 2019 & 30568355 & RCT & 150 & Not exclusively & Non-significant \\
\hline 2018 & 30220024 & Meta-analysis & 1016 & Not exclusively & Significantly favorable, Significantly favorable in RIF (subgroup analysis) \\
\hline 2018 & 30027145 & RCT & 50 & Not exclusively & Non-significant \\
\hline 2017 & 28632452 & Meta-analysis & & Not exclusively & Significantly favorable, Significantly favorable in RIF (subgroup analysis) \\
\hline 2017 & 28458165 & Meta-analysis & 255 & Not exclusively & Significantly favorable Significantly favorable in RIF (subgroup analysis) \\
\hline 2017 & 27874292 & Non-randomized & 62 & Not exclusively & Non-significant \\
\hline 2017 & 28791050 & $\mathrm{RCT}$ & 28 & Not exclusively & Significantly improved implantation rate \\
\hline 2016 & 27659067 & Meta-analysis & 1101 & Not exclusively & Significantly favorable (sc) Non-significant (intrauterine) \\
\hline 2016 & 28066833 & $\mathrm{RCT}$ & 100 & Yes & Non-significant pregnancy rate \\
\hline 2016 & 27981253 & $\mathrm{RCT}$ & 90 & Yes & Significantly favorable in RIF \\
\hline 2016 & 27326420 & RCT & 100 & & Non-significant \\
\hline 2016 & 26980809 & $\mathrm{RCT}$ & 112 & Yes & Significantly favorable in RIF \\
\hline 2014 & 24424357 & $\mathrm{RCT}$ & 141 & Not exclusively & Non-significant \\
\hline 2014 & 25469123 & Non-randomized & 68 & Not exclusively & Non-significant \\
\hline 2014 & 23885097 & Non-randomized & 59 & Not exclusively & Non-significant \\
\hline
\end{tabular}

TABLE 6 | Salient features of the included studies on atosiban as an intervention in improving endometrial receptivity.

\begin{tabular}{|c|c|c|c|c|c|}
\hline Year & PMID & Publication type & Participants & RIF & Outcome \\
\hline 2020 & 32046434 & Non-randomized & 403 & Not exclusively & Significantly favorable in RIF (subgroup analysis) \\
\hline 2019 & 30791824 & $\mathrm{RCT}$ & 203 & Not exclusively & Significantly favorable in case of difficult ET \\
\hline 2017 & 28422984 & Meta-analysis & 1754 & Not exclusively & Significantly favorable in RIF (subgroup analysis) \\
\hline 2016 & 27143518 & $\mathrm{RCT}$ & 240 & Not exclusively & Significantly favorable \\
\hline 2014 & 25336707 & $\mathrm{RCT}$ & 800 & Not exclusively & Non-significant \\
\hline 2012 & 22818095 & Non-randomized & 71 & Yes & Significantly favorable in RIF \\
\hline 2011 & 21791296 & Non-randomized & 150 & Yes & Significantly favorable in RIF \\
\hline 2010 & 20638340 & $\mathrm{RCT}$ & 180 & Not exclusively & Significantly favorable \\
\hline
\end{tabular}

weakening the level of evidence of the reported findings. Only two non-randomized studies on RIF patients report a significant benefit after atosiban treatment (Chou et al., 2011; Lan et al., 2012). Interestingly, both the meta-analysis (Huang et al., 2017b) and a recent prospective study on women with at least one IVF effort (Wu et al., 2020), after performing subgroup analysis, report significant improvement on the reproductive outcomes in case of RIF patients. Taking into consideration the fact that subgroup analysis may include a risk of statistical bias, this observation implies a potential role for atosiban when treating women with RIF. Properly powered randomized controlled trials are needed to delineate atosiban efficacy.

\section{Antibiotics for Chronic Endometritis}

The field of chronic endometritis (CE) is emerging, especially in unexplained RIF, since CE presents a subtle course that can be easily missed. Few reports have been published so far upon antibiotic treatment in case of $\mathrm{CE}$ diagnosed in women with unexplained RIF (Johnston-MacAnanny et al.,
2010; Yang et al., 2014; Cicinelli et al., 2015; Tersoglio et al., 2015; Bouet et al., 2016; Kitaya et al., 2017; Zhang et al., 2019). Analyzing this therapeutic approach, it can be easily seen that there is substantial heterogeneity in terms of antibiotic treatment: antibiotics are offered according to microbial cultures or empirically, including penicillins, cephalosporins, kinolones, metronidazole, clindamycin, tetracyclines (mainly doxycycline), and aminoglycodides (gentamycine). The course of treatment also varies. Interestingly, apart from the standard per os treatment, the intrauterine approach has also been presented (Zhang et al., 2019). All the studies published so far are non-randomized thus producing low level of evidence. Two recent meta-analyses have summarized the existing results, supporting antibiotic treatment as an approach to improve reproductive outcomes in women with RIF (Vitagliano et al., 2018b; Huang et al., 2020b). Additionally, it is highlighted that a stringent approach in setting the diagnosis may reveal lower CE incidences and reproductive outcomes compared to approaches with broader diagnostic criteria (Huang et al., 2020b). 
Long-term treatments seem more beneficial compared to shortterm antibiotic courses (Huang et al., 2020b).

\section{Efforts to Intervene in Case of Endometrial Dysbiosis}

The concept of endometrial dysbiosis is emerging during the last 5 years. Several approaches have been proposed as potentially effective in restoring normal endometrial microbiome. However it must be taken under consideration the fact that to date there is no core endometrial microbiome, therefore restoring to normal could be a matter of question (Molina et al., 2020). Microbiome restoration is initially approached by the administration of antibiotics, considering that most of the time dysbiotic microbiota may include pathogens well-controlled by standard anti-microbial agents (Kyono et al., 2019). Several routes of administration have been proposed so far including oral, vaginal and intrauterine (Molina et al., 2020). Additionally, the administration of pro- and pre-biotics has been tested as auxiliary means of maintaining or amplifying the eubiotic bacteria. Of note is the mode of action of pro-biotics-bacteria involved in normal microbiome, administered in the context to colonize in an antagonizing fashion the dysbiotic microbial counterparts (Chenoll et al., 2019). On the contrary, pre-biotics are molecules uptaken by normal microbial populations, facilitating their survival. Pre- and pro-biotics are usually co-administered with antibiotics. A recent study investigated different routes of antibiotic administration (metronidazole) combined with prebiotic (lactoferrin) and probiotic administration, concluded that the combined vaginal and oral metronidazole administration along with a vaginal probiotic treatment could restore normal

\section{REFERENCES}

Aaleyasin, A., Aghahosseini, M., Rashidi, M., Safdarian, L., Sarvi, F., Najmi, Z., et al. (2015). In vitro fertilization outcome following embryo transfer with or without preinstillation of human chorionic gonadotropin into the uterine cavity: a randomized controlled trial. Gynecol. Obstet. Invest. 79, 201-205. doi: 10.1159/000363235

Achache, H., Tsafrir, A., Prus, D., Reich, R., and Revel, A. (2010). Defective endometrial prostaglandin synthesis identified in patients with repeated implantation failure undergoing in vitro fertilization. Fertil. Steril. 94, 12711278. doi: 10.1016/j.fertnstert.2009.07.1668

Al-Nasiry, S., Ambrosino, E., Schlaepfer, M., Morré, S. A., Wieten, L., Voncken, J. W., et al. (2020). The Interplay Between Reproductive Tract Microbiota and Immunological System in Human Reproduction. Front. Immunol. 11:378. doi: 10.3389/fimmu.2020.00378

Aleyasin, A., Abediasl, Z., Nazari, A., and Sheikh, M. (2016). Granulocyte colonystimulating factor in repeated IVF failure, a randomized trial. Reproduction 151, 637-642. doi: 10.1530/rep-16-0046

Ali, S. B., Jeelall, Y., Pennell, C. E., Hart, R., McLean-Tooke, A., and Lucas, M. (2018). The role of immunological testing and intervention in reproductive medicine: A fertile collaboration? Am. J. Reprod. Immunol. 79:12784. doi: 10. 1111/aji.12784

Altmäe, S., and Aghajanova, L. (2019). Growth Hormone and Endometrial Receptivity. Front. Endocrinol. 10:653. doi: 10.3389/fendo.2019.00653

Altmäe, S., Mendoza-Tesarik, R., Mendoza, C., Mendoza, N., Cucinelli, F., and Tesarik, J. (2018). Effect of Growth Hormone on Uterine Receptivity in Women With Repeated Implantation Failure in an Oocyte Donation Program: A Randomized Controlled Trial. J. Endocr. Soc. 2, 96-105. doi: 10.1210/js.201700359 endometrial microbiome in women with RIF (Kadogami et al., 2020). New approaches have been proposed as promising, lacking evidence at the moment. Vaginal microbiome transplants have been considered as a possibility. A recent study showed the restoration of the vaginal microbiome in case of refractory vaginosis (Lev-Sagie et al., 2019), a fact that could imply further colonization of the endometrial cavity by the ascending route. Taking all the above into consideration, it is clear that there is no evidence at the moment to support both endometrial microbiome assessment and thereafter interventions toward restoration to normal. Such efforts have to be strictly performed in the frame of a research protocol.

\section{CONCLUSION}

All the novel interventions, aiming to treat unexplained RIF, lack the evidence required in order to be incorporated to standard of care. Properly designed randomized trials are therefore needed to clarify which could be beneficial in RIF treatment. RIF patients should be properly informed regarding potential benefits and risks.

\section{AUTHOR CONTRIBUTIONS}

AM had the idea for this review. AM, FM, and TV participated in literature search, drafted, and critically revised the manuscript, approved the final version of the manuscript. All authors contributed to the article and approved the submitted version.

Arefi, S., Fazeli, E., Esfahani, M., Borhani, N., Yamini, N., Hosseini, A., et al. (2018). Granulocyte-colony stimulating factor may improve pregnancy outcome in patients with history of unexplained recurrent implantation failure: An RCT. Int. J. Reprod. Biomed. 16, 299-304.

Arora, G., and Arora, S. (2020). Platelet Rich Plasma - where do we stand today? A critical narrative review and analysis. Dermatol. Ther. 2020:e14343. doi: 10. 1111/dth.14343

Baba, K., Yamazaki, Y., Sone, Y., Sugimoto, Y., Moriyama, K., Sugimoto, T., et al. (2019). An in vitro long-term study of cryopreserved umbilical cord blood-derived platelet-rich plasma containing growth factors-PDGF-BB, TGF$\beta$, and VEGF. J. Craniomaxillofac. Surg. 47, 668-675. doi: 10.1016/j.jcms.2019. 01.020

Baker, J. M., Chase, D. M., and Herbst-Kralovetz, M. M. (2018). Uterine Microbiota: Residents, Tourists, or Invaders? Front. Immunol. 9:208. doi: 10. 3389/fimmu.2018.00208

Bakirarar, B., Kent, E., Makrigiannakis, A., Gurgan, T., Jain, S., Mahey, R., et al. (2018). Effect of Intrauterine Perfusion of Granulocyte Colony-stimulating Factor on Endometrial parameters and In Vitro Fertilization Outcome in Women Undergoing In Vitro Fertilization/Intracytoplasmic Sperm Injection Cycles: A Randomized Controlled Trial. Sci. Rep. 11, 254-260.

Barad, D. H., Yu, Y., Kushnir, V. A., Shohat-Tal, A., Lazzaroni, E., Lee, H. J., et al. (2014). A randomized clinical trial of endometrial perfusion with granulocyte colony-stimulating factor in in vitro fertilization cycles: impact on endometrial thickness and clinical pregnancy rates. Fertil. Steril. 101, 710-715. doi: 10.1016/ j.fertnstert.2013.12.016

Barash, A., Dekel, N., Fieldust, S., Segal, I., Schechtman, E., and Granot, I. (2003). Local injury to the endometrium doubles the incidence of successful pregnancies in patients undergoing in vitro fertilization. Fertil. Steril. 79, 1317-1322. doi: 10.1016/s0015-0282(03)00345-5 
Bashiri, A., Halper, K. I., and Orvieto, R. (2018). Recurrent Implantation Failureupdate overview on etiology, diagnosis, treatment and future directions. Reprod. Biol. Endocrinol. 16:121. doi: 10.1186/s12958-018-0414-2

Bassil, R., Casper, R., Samara, N., Hsieh, T. B., Barzilay, E., Orvieto, R., et al. (2018). Does the endometrial receptivity array really provide personalized embryo transfer? J. Assist Reprod. Genet. 35, 1301-1305. doi: 10.1007/s10815-0181190-9

Ben Rafael, Z. (2020). Repeated implantation failure (RIF): an iatrogenic meaningless definition that generates unnecessary and costly use of add-on procedures. Hum. Reprod. 35, 1479-1483. doi: 10.1093/humrep/deaa134

Benner, M., Ferwerda, G., Joosten, I., and van der Molen, R. G. (2018). How uterine microbiota might be responsible for a receptive, fertile endometrium. Hum. Reprod. Update 24, 393-415. doi: 10.1093/humupd/dmy012

Bielfeld, A. P., Pour, S. J., Poschmann, G., Stühler, K., Krüssel, J. S., and BastonBüst, D. M. (2019). A Proteome Approach Reveals Differences between Fertile Women and Patients with Repeated Implantation Failure on Endometrial Level $^{-}$Does hCG Render the Endometrium of RIF Patients? Int. J. Mol. Sci. 20:20020425. doi: 10.3390/ijms20020425

Bonduelle, M. L., Dodd, R., Liebaers, I., Van Steirteghem, A., Williamson, R., and Akhurst, R. (1988). Chorionic gonadotrophin-beta mRNA, a trophoblast marker, is expressed in human 8-cell embryos derived from tripronucleate zygotes. Hum. Reprod. 3, 909-914.

Boonsuk, S., Petyim, S., Prechapanich, J., Choavaratana, R., Hafezi, M., Madani, T., et al. (2018). The effect of intrauterine human chorionic gonadotropin flushing on live birth rate after vitrified-warmed embryo transfer in programmed cycles: a randomized clinical trial. Arch. Gynecol. Obstet. 297, 1571-1576.

Bouet, P. E., El Hachem, H., Monceau, E., Gariépy, G., Kadoch, I. J., and Sylvestre, C. (2016). Chronic endometritis in women with recurrent pregnancy loss and recurrent implantation failure: prevalence and role of office hysteroscopy and immunohistochemistry in diagnosis. Fertil. Steril. 105, 106-110. doi: 10.1016/j. fertnstert.2015.09.025

Bracewell-Milnes, T., Saso, S., Nikolaou, D., Norman-Taylor, J., Johnson, M., and Thum, M. Y. (2018). Investigating the effect of an abnormal cervico-vaginal and endometrial microbiome on assisted reproductive technologies: A systematic review. Am. J. Reprod. Immunol. 80:e13037. doi: 10.1111/aji.13037

Cakiroglu, Y., and Tiras, B. (2020). Determining diagnostic criteria and cause of recurrent implantation failure. Curr. Opin. Obstet. Gynecol. 32, 198-204. doi: 10.1097/gco.0000000000000620

Chang, Y., Li, J., Chen, Y., Wei, L., Yang, X., Shi, Y., et al. (2015). Autologous platelet-rich plasma promotes endometrial growth and improves pregnancy outcome during in vitro fertilization. Int. J. Clin. Exp. Med. 8, 1286-1290.

Chang, Y., Li, J., Wei, L. N., Pang, J., Chen, J., and Liang, X. (2019). Autologous platelet-rich plasma infusion improves clinical pregnancy rate in frozen embryo transfer cycles for women with thin endometrium. Medicine 98:e14062. doi: 10.1097/md.0000000000014062

Chenoll, E., Moreno, I., Sánchez, M., Garcia-Grau, I., Silva, Á, González-Monfort, M., et al. (2019). Selection of New Probiotics for Endometrial Health. Front. Cell Infect. Microbiol. 9:114. doi: 10.3389/fcimb.2019.00114

Choi, Y., Kim, H. R., Lim, E. J., Park, M., Yoon, J. A., Kim, Y. S., et al. (2016). Integrative Analyses of Uterine Transcriptome and MicroRNAome Reveal Compromised LIF-STAT3 Signaling and Progesterone Response in the Endometrium of Patients with Recurrent/Repeated Implantation Failure (RIF). PLoS One 11:e0157696. doi: 10.1371/journal.pone.0157696

Chou, P. Y., Wu, M. H., Pan, H. A., Hung, K. H., and Chang, F. M. (2011). Use of an oxytocin antagonist in in vitro fertilization-embryo transfer for women with repeated implantation failure: a retrospective study. Taiwan J. Obstet. Gynecol. 50, 136-140. doi: 10.1016/j.tjog.2011.04.003

Cicinelli, E., Matteo, M., Tinelli, R., Lepera, A., Alfonso, R., Indraccolo, U., et al. (2015). Prevalence of chronic endometritis in repeated unexplained implantation failure and the IVF success rate after antibiotic therapy. Hum. Reprod. 30, 323-330. doi: 10.1093/humrep/deu292

Clooney, A. G., Fouhy, F., Sleator, R. D., Stanton, C., Cotter, P. D., et al. (2016). Comparing Apples and Oranges?: Next Generation Sequencing and Its Impact on Microbiome Analysis. PLoS One 11:e0148028. doi: 10.1371/journal.pone. 0148028

Coksuer, H., Akdemir, Y., and Ulas Barut, M. (2019). Improved in vitro fertilization success and pregnancy outcome with autologous platelet-rich plasma treatment in unexplained infertility patients that had repeated implantation failure history. Gynecol. Endocrinol. 35, 815-818. doi: 10.1080/09513590.2019.1597344

Cole, L. A. (2010). Hyperglycosylated hCG, a review. Placenta 31, 653-664. doi: 10.1016/j.placenta.2010.06.005

Coughlan, C. (2018). What to do when good-quality embryos repeatedly fail to implant. Best Pract. Res. Clin. Obstet. Gynaecol. 53, 48-59. doi: 10.1016/j. bpobgyn.2018.07.004

Coughlan, C., Ledger, W., Wang, Q., Liu, F., Demirol, A., Gurgan, T., et al. (2014a). Recurrent implantation failure: definition and management. Reprod. Biomed. Online 28, 14-38. doi: 10.1016/j.rbmo.2013.08.011

Coughlan, C., Walters, S., Ledger, W., and Li, T. C. (2014b). A comparison of psychological stress among women with and without reproductive failure. Int. J. Gynaecol. Obstet. 124, 143-147. doi: 10.1016/j.ijgo.2013.08.006

Craciunas, L., Tsampras, N., Raine-Fenning, N., and Coomarasamy, A. (2018). Intrauterine administration of human chorionic gonadotropin (hCG) for subfertile women undergoing assisted reproduction. Cochrane Database Syst. Rev. 10:Cd011537. doi: 10.1002/14651858.CD011537.pub3

Cui, N., Li, A. M., Luo, Z. Y., Zhao, Z. M., Xu, Y. M., Zhang, J., et al. (2019). Effects of growth hormone on pregnancy rates of patients with thin endometrium. J. Endocrinol. Invest. 42, 27-35. doi: 10.1007/s40618-0180877-1

Davari-Tanha, F., Shahrokh Tehraninejad, E., Ghazi, M., and Shahraki, Z. (2016). The role of G-CSF in recurrent implantation failure: A randomized double blind placebo control trial. Obstet. Gynecol. Int. 14, 737-742.

Dehghani Firouzabadi, R., Janati, S., and Razi, M. H. (2016). The effect of intrauterine human chorionic gonadotropin injection before embryo transfer on the implantation and pregnancy rate in infertile patients: A randomized clinical trial. Int. J. Reprod. Biomed. 14, 657-664.

Demiral Keleş, I., Ülgen, E., Erkan, M. B., Çelik, S. E., Aydın, Y., Önem, A. N., et al. (2020). Comparison of endometrial prostanoid profiles in three infertile subgroups: the missing part of receptivity? Fertil. Steril. 113, 670.e-678.e. doi: 10.1016/j.fertnstert.2019.10.017

Diao, L. H., Li, G. G., Zhu, Y. C., Tu, W. W., Huang, C. Y., Lian, R. C., et al. (2017). Human chorionic gonadotropin potentially affects pregnancy outcome in women with recurrent implantation failure by regulating the homing preference of regulatory T cells. Am. J. Reprod. Immunol. 77:12618. doi: 10.1111/aji.12618

Donoghue, J. F., Paiva, P., Teh, W. T., Cann, L. M., Nowell, C., Rees, H., et al. (2019). Endometrial uNK cell counts do not predict successful implantation in an IVF population. Hum. Reprod. 34, 2456-2466. doi: 10.1093/humrep/dez194

Eftekhar, M., Hosseinisadat, R., Baradaran, R., and Naghshineh, E. (2016a). Effect of granulocyte colony stimulating factor (G-CSF) on IVF outcomes in infertile women: An RCT. Int. J. Reprod. Biomed. 14, 341-346.

Eftekhar, M., Miraj, S., Farid Mojtahedi, M., and Neghab, N. (2016b). Efficacy of Intrauterine infusion of granulocyte colony stimulating factor on patients with history of implantation failure: A randomized control trial. Int. J. Reprod. Biomed. 14, 687-690.

Eftekhar, M., Neghab, N., Naghshineh, E., and Khani, P. (2018). Can autologous platelet rich plasma expand endometrial thickness and improve pregnancy rate during frozen-thawed embryo transfer cycle? A randomized clinical trial. Taiwan J. Obstet. Gynecol. 57, 810-813. doi: 10.1016/j.tjog.2018.10.007

Einenkel, R., Zygmunt, M., and Muzzio, D. O. (2019). Microorganisms in the healthy upper reproductive tract: from denial to beneficial assignments for reproductive biology. Reprod. Biol. 19, 113-118. doi: 10.1016/j.repbio.2019. 04.001

Eisenhofer, R., Minich, J. J., Marotz, C., Cooper, A., Knight, R., and Weyrich, L. S. (2019). Contamination in Low Microbial Biomass Microbiome Studies: Issues and Recommendations. Trends Microbiol. 27, 105-117. doi: 10.1016/j.tim.2018. 11.003

El-Toukhy, T., Sunkara, S., and Khalaf, Y. (2012). Local endometrial injury and IVF outcome: a systematic review and meta-analysis. Reprod. Biomed. Online 25, 345-354. doi: 10.1016/j.rbmo.2012.06.012

Evans, J., and Salamonsen, L. A. (2013). Too much of a good thing? Experimental evidence suggests prolonged exposure to hCG is detrimental to endometrial receptivity. Hum. Reprod. 28, 1610-1619. doi: 10.1093/humrep/det055

Fan, X., Li, X., Li, Y., Liao, J., Chen, H., Li, Y., et al. (2019). Endometrial CD138 count appears to be a negative prognostic indicator for patients who have 
experienced previous embryo transfer failure. Fertil. Steril. 112, 1103-1111. doi: 10.1016/j.fertnstert.2019.08.006

Fazleabas, A. T., Donnelly, K. M., Srinivasan, S., Fortman, J. D., and Miller, J. B. (1999). Modulation of the baboon (Papio anubis) uterine endometrium by chorionic gonadotrophin during the period of uterine receptivity. Proc. Natl. Acad. Sci. U S A. 96, 2543-2548.

Fluhr, H., Bischof-Islami, D., Krenzer, S., Licht, P., Bischof, P., and Zygmunt, M. (2008a). Human chorionic gonadotropin stimulates matrix metalloproteinases2 and -9 in cytotrophoblastic cells and decreases tissue inhibitor of metalloproteinases-1, -2 , and -3 in decidualized endometrial stromal cells. Fertil. Steril. 90(4 Suppl.), 1390-1395. doi: 10.1016/j.fertnstert.2007.08.023

Fluhr, H., Carli, S., Deperschmidt, M., Wallwiener, D., Zygmunt, M., and Licht, P. (2008b). Differential effects of human chorionic gonadotropin and decidualization on insulin-like growth factors-I and -II in human endometrial stromal cells. Fertil. Steril. 90(4 Suppl.), 1384-1389. doi: 10.1016/j.fertnstert. 2007.07.1357

Fogle, R. H., Li, A., and Paulson, R. J. (2010). Modulation of HOXA10 and other markers of endometrial receptivity by age and human chorionic gonadotropin in an endometrial explant model. Fertil. Steril. 93, 1255-1259. doi: 10.1016/j. fertnstert.2008.11.002

Frantz, S., Parinaud, J., Kret, M., Rocher-Escriva, G., Papaxanthos-Roche, A., Creux, H., et al. (2019). Decrease in pregnancy rate after endometrial scratch in women undergoing a first or second in vitro fertilization. A multicenter randomized controlled trial. Hum. Reprod. 34, 92-99. doi: 10.1093/humrep/ dey334

Gao, M., Jiang, X., Li, B., Li, L., Duan, M., Zhang, X., et al. (2019). Intrauterine injection of human chorionic gonadotropin before embryo transfer can improve in vitro fertilization-embryo transfer outcomes: a meta-analysis of randomized controlled trials. Fertil. Steril. 112, 89.e-97.e. doi: 10.1016/j. fertnstert.2019.02.027

Gkrozou, F., Tsonis, O., Dimitriou, E., and Paschopoulos, M. (2020). In women with chronic or subclinical endometritis is hysteroscopy suitable for setting the diagnosis? A systematic review. J. Obstet. Gynaecol. Res. 46, 1639-1650. doi: $10.1111 /$ jog. 14360

Glassing, A., Dowd, S. E., Galandiuk, S., Davis, B., and Chiodini, R. J. (2016). Inherent bacterial DNA contamination of extraction and sequencing reagents may affect interpretation of microbiota in low bacterial biomass samples. Gut Pathog. 8:24. doi: 10.1186/s13099-016-0103-7

Gnainsky, Y., Granot, I., Aldo, P., Barash, A., Or, Y., Mor, G., et al. (2015). Biopsy-induced inflammatory conditions improve endometrial receptivity: the mechanism of action. Reproduction 149, 75-85. doi: 10.1530/rep-14-0395

Gnainsky, Y., Granot, I., Aldo, P. B., Barash, A., Or, Y., Schechtman, E., et al. (2010). Local injury of the endometrium induces an inflammatory response that promotes successful implantation. Fertil. Steril. 94, 2030-2036. doi: 10.1016/j. fertnstert.2010.02.022

Granot, I., Gnainsky, Y., and Dekel, N. (2012). Endometrial inflammation and effect on implantation improvement and pregnancy outcome. Reproduction 144, 661-668. doi: 10.1530/rep-12-0217

Gui, J., Xu, W., Yang, J., Feng, L., and Jia, J. (2019). Impact of local endometrial injury on in vitro fertilization/intracytoplasmic sperm injection outcomes: A systematic review and meta-analysis. J. Obstet. Gynaecol. Res. 45, 57-68. doi: 10.1111/jog. 13854

Guibourdenche, J., Handschuh, K., Tsatsaris, V., Gerbaud, P., Leguy, M. C., Muller, F., et al. (2010). Hyperglycosylated hCG is a marker of early human trophoblast invasion. J. Clin. Endocrinol. Metab. 95, E240-E244. doi: 10.1210/jc.2010-0138

Guo, F., Si, C., Zhou, M., Wang, J., Zhang, D., Leung, P. C. K., et al. (2018). Decreased PECAM1-mediated TGF- $\beta 1$ expression in the mid-secretory endometrium in women with recurrent implantation failure. Hum. Reprod. 33, 832-843. doi: 10.1093/humrep/dey022

Hafezi, M., Madani, T., Arabipoor, A., Zolfaghari, Z., Sadeghi, M., and Ramezanali, F. (2018). The effect of intrauterine human chorionic gonadotropin flushing on live birth rate after vitrified-warmed embryo transfer in programmed cycles: a randomized clinical trial. Arch. Gynecol. Obstet. 297, 1571-1576. doi: 10.1007/ s00404-018-4752-2

Hashii, K., Fujiwara, H., Yoshioka, S., Kataoka, N., Yamada, S., Hirano, T., et al. (1998). Peripheral blood mononuclear cells stimulate progesterone production by luteal cells derived from pregnant and non-pregnant women: possible involvement of interleukin- 4 and interleukin-10 in corpus luteum function and differentiation. Hum. Reprod. 13, 2738-2744. doi: 10.1093/humrep/13.10.2738

He, Y., Wu, H., He, X., Xing, Q., Zhou, P., Cao, Y., et al. (2016). Administration of atosiban in patients with endometriosis undergoing frozen-thawed embryo transfer: a prospective, randomized study. Fertil. Steril. 106, 416-422. doi: 10. 1016/j.fertnstert.2016.04.019

Hong, K. H., Forman, E. J., Werner, M. D., Upham, K. M., Gumeny, C. L., Winslow, A. D., et al. (2014). Endometrial infusion of human chorionic gonadotropin at the time of blastocyst embryo transfer does not impact clinical outcomes: a randomized, double-blind, placebo-controlled trial. Fertil. Steril. 102, 1591.e1595.e. doi: 10.1016/j.fertnstert.2014.08.006

Hou, W., Shi, G., Cai, B., Ding, C., Song, J., Zhang, X., et al. (2018). Effect of intrauterine injection of human chorionic gonadotropin before fresh embryo transfer on IVF and ICSI outcomes: a meta-analysis. Arch. Gynecol. Obstet. 298, 1061-1069. doi: 10.1007/s00404-018-4923-1

Huang, P., Wei, L., and Li, X. (2017a). A study of intrauterine infusion of human chorionic gonadotropin (hCG) before frozen-thawed embryo transfer after two or more implantation failures. Gynecol. Endocrinol. 33, 67-69. doi: 10.1080/ 09513590.2016.1207164

Huang, P., Yao, C., Wei, L., and Lin, Z. (2020a). The intrauterine perfusion of granulocyte-colony stimulating factor (G-CSF) before frozen-thawed embryo transfer in patients with two or more implantation failures. Hum. Fertil. 2020, 1-5. doi: 10.1080/14647273.2020.1811904

Huang, Q. Y., Rong, M. H., Lan, A. H., Lin, X. M., Lin, X. G., He, R. Q., et al. (2017b). The impact of atosiban on pregnancy outcomes in women undergoing in vitro fertilization-embryo transfer: A meta-analysis. PLoS One 12:e175501. doi: 10.1371/journal.pone.0175501

Huang, W., Liu, B., He, Y., Xie, Y., Liang, T., Bi, Y., et al. (2020b). Variation of diagnostic criteria in women with chronic endometritis and its effect on reproductive outcomes: A systematic review and meta-analysis. J. Reprod. Immunol. 140:103146. doi: 10.1016/j.jri.2020.103146

Jiang, Y., Zhao, Q., Zhang, Y., Zhou, L., Lin, J., Chen, Y., et al. (2020). Treatment of G-CSF in unexplained, repeated implantation failure: A systematic review and meta-analysis. J. Gynecol. Obstet. Hum. Reprod. 2020:101866. doi: 10.1016/ j.jogoh.2020.101866

Johnston-MacAnanny, E. B., Hartnett, J., Engmann, L. L., Nulsen, J. C., Sanders, M. M., and Benadiva, C. A. (2010). Chronic endometritis is a frequent finding in women with recurrent implantation failure after in vitro fertilization. Fertil. Steril. 93, 437-441. doi: 10.1016/j.fertnstert.2008.12.131

Kadogami, D., Nakaoka, Y., and Morimoto, Y. (2020). Use of a vaginal probiotic suppository and antibiotics to influence the composition of the endometrial microbiota. Reprod. Biol. 20, 307-314. doi: 10.1016/j.repbio.2020.07.001

Kalem, Z., Namli Kalem, M., Bakirarar, B., Kent, E., Makrigiannakis, A., and Gurgan, T. (2020). Intrauterine G-CSF Administration in Recurrent Implantation Failure (RIF): An Rct. Sci. Rep. 10:5139. doi: 10.1038/s41598-02061955-7

Kalma, Y., Granot, I., Gnainsky, Y., Or, Y., Czernobilsky, B., Dekel, N., et al. (2009). Endometrial biopsy-induced gene modulation: first evidence for the expression of bladder-transmembranal uroplakin Ib in human endometrium. Fertil. Steril. 91, 1042-1049. doi: 10.1016/j.fertnstert.2008.01.043

Kamath, M. S., Chittawar, P. B., Kirubakaran, R., and Mascarenhas, M. (2017). Use of granulocyte-colony stimulating factor in assisted reproductive technology: A systematic review and meta-analysis. Eur. J. Obstet. Gynecol. Reprod. Biol. 214, 16-24. doi: 10.1016/j.ejogrb.2017.04.022

Kamath, M. S., Kirubakaran, R., and Sunkara, S. K. (2020). Granulocytecolony stimulating factor administration for subfertile women undergoing assisted reproduction. Cochrane Database Syst. Rev. 1:Cd013226. doi: 10.1002/ 14651858.CD013226.pub2

Kara, M., Sabah Ozcan, S., Aran, T., Kara, O., and Yilmaz, N. (2019). Decreased expression of LIF mRNA in patients withmyoma uteri. J. Cell Biochem. 120, 3423-3427. doi: 10.1002/jcb.27613

Kasius, J. C., Broekmans, F. J., Sie-Go, D. M., Bourgain, C., Eijkemans, M. J., Fauser, B. C., et al. (2012). The reliability of the histological diagnosis of endometritis in asymptomatic IVF cases: a multicenter observer study. Hum. Reprod. 27, 153-158. doi: 10.1093/humrep/der341

Kayisli, U. A., Selam, B., Guzeloglu-Kayisli, O., Demir, R., and Arici, A. (2003). Human chorionic gonadotropin contributes to maternal immunotolerance and 
endometrial apoptosis by regulating Fas-Fas ligand system. J. Immunol. 171, 2305-2313.

Kim, D., Hofstaedter, C. E., Zhao, C., Mattei, L., Tanes, C., Clarke, E., et al. (2017). Optimizing methods and dodging pitfalls in microbiome research. Microbiome 5:52. doi: 10.1186/s40168-017-0267-5

Kitaya, K., Matsubayashi, H., Takaya, Y., Nishiyama, R., Yamaguchi, K., Takeuchi, T., et al. (2017). Live birth rate following oral antibiotic treatment for chronic endometritis in infertile women with repeated implantation failure. Am. J. Reprod. Immunol. 78:12719. doi: 10.1111/aji.12719

Koot, Y. E., van Hooff, S. R., Boomsma, C. M., van Leenen, D., Groot Koerkamp, M. J., Goddijn, M., et al. (2016). An endometrial gene expression signature accurately predicts recurrent implantation failure after IVF. Sci. Rep. 6:19411. doi: $10.1038 /$ srep 19411

Kyono, K., Hashimoto, T., Kikuchi, S., Nagai, Y., and Sakuraba, Y. (2019). A pilot study and case reports on endometrial microbiota and pregnancy outcome: An analysis using $16 \mathrm{~S}$ rRNA gene sequencing among IVF patients, and trial therapeutic intervention for dysbiotic endometrium. Reprod. Med. Biol. 18, 72-82. doi: $10.1002 / \mathrm{rmb} 2.12250$

Lan, K. C., Lin, P. Y., Chang, Y. C., Chen, Y. J., Tsai, Y. R., Ismaeil Mohamed, I. S., et al. (2019). Growth hormone supplementation may improve the pregnancy rate and endometrial receptivity among women aged more than 40 years undergoing in vitro fertilization. Biomed. J. 42, 411-416. doi: 10.1016/j.bj.2019. 05.003

Lan, V. T., Khang, V. N., Nhu, G. H., and Tuong, H. M. (2012). Atosiban improves implantation and pregnancy rates in patients with repeated implantation failure. Reprod. Biomed. Online 25, 254-260. doi: 10.1016/j.rbmo.2012.05.014

Lang, S., Herrmann, M., Pfeifer, C., Brockhoff, G., Zellner, J., Nerlich, M., et al. (2017). Leukocyte-reduced platelet-rich plasma stimulates the in vitro proliferation of adipose-tissue derived mesenchymal stem cells depending on PDGF signaling. Clin. Hemorheol. Microcirc. 67, 183-196. doi: 10.3233/ch170246

Laokirkkiat, P., and Thanaboonyawat, I. (2019). Increased implantation rate after intrauterine infusion of a small volume of human chorionic gonadotropin at the time of embryo transfer: a randomized, double-blind controlled study. Arch. Gynecol. Obstet. 299, 267-275. doi: 10.1007/s00404-018-4962-7

Lebovitz, O., and Orvieto, R. (2014). Treating patients with "thin" endometrium an ongoing challenge. Gynecol. Endocrinol. 30, 409-414. doi: 10.3109/09513590. 2014.906571

Lédée, N., Petitbarat, M., Chevrier, L., Vitoux, D., Vezmar, K., Rahmati, M., et al. (2016). The Uterine Immune Profile May Help Women With Repeated Unexplained Embryo Implantation Failure After In Vitro Fertilization. Am. J. Reprod. Immunol. 75, 388-401. doi: 10.1111/aji.12483

Lensen, S., Osavlyuk, D., Armstrong, S., Stadelmann, C., Hennes, A., Napier, E., et al. (2019a). A Randomized Trial of Endometrial Scratching before In Vitro Fertilization. N. Engl. J. Med. 380, 325-334. doi: 10.1056/NEJMoa1808737

Lensen, S., Venetis, C., Ng, E. H. Y., Young, S. L., Vitagliano, A., Macklon, N. S., et al. (2019b). Should we stop offering endometrial scratching prior to in vitro fertilization? Fertil. Steril. 111, 1094-1101. doi: 10.1016/j.fertnstert.2019.04.017

Lev-Sagie, A., Goldman-Wohl, D., Cohen, Y., Dori-Bachash, M., Leshem, A., Mor, U., et al. (2019). Vaginal microbiome transplantation in women with intractable bacterial vaginosis. Nat. Med. 25, 1500-1504. doi: 10.1038/s41591-019-0600-6

Li, J., Mo, S., and Chen, Y. (2017a). The effect of G-CSF on infertile women undergoing IVF treatment: A meta-analysis. Syst. Biol. Reprod. Med. 63, 239247. doi: $10.1080 / 19396368.2017 .1287225$

Li, S., Wang, J., Cheng, Y., Zhou, D., Yin, T., Xu, W., et al. (2017b). Intrauterine administration of hCG-activated autologous human peripheral blood mononuclear cells (PBMC) promotes live birth rates in frozen/thawed embryo transfer cycles of patients with repeated implantation failure. J. Reprod. Immunol. 119, 15-22. doi: 10.1016/j.jri.2016.11.006

Li, W., Suke, S., Wertaschnigg, D., Lensen, S., Wang, R., Gurrin, L., et al. (2019). Randomised controlled trials evaluating endometrial scratching: assessment of methodological issues. Hum. Reprod. 34, 2372-2380. doi: 10.1093/humrep/ dez207

Li, Y., Xu, S., Yu, S., Huang, C., Lin, S., Chen, W., et al. (2020). Diagnosis of chronic endometritis: How many CD138(+) cells/HPF in endometrial stroma affect pregnancy outcome of infertile women? Am. J. Reprod. Immunol. 2020:e13369. doi: $10.1111 /$ aji.13369
Liang, P. Y., Yin, B., Cai, J., Hu, X. D., Song, C., Wu, T. H., et al. (2015). Increased circulating Th1/Th2 ratios but not other lymphocyte subsets during controlled ovarian stimulation are linked to subsequent implantation failure after transfer of in vitro fertilized embryos. Am. J. Reprod. Immunol. 73, 12-21. doi: 10.1111/ aji. 12320

Licht, P., Losch, A., Dittrich, R., Neuwinger, J., Siebzehnrubl, E., and Wildt, L. (1998). Novel insights into human endometrial paracrinology and embryomaternal communication by intrauterine microdialysis. Hum. Reprod. Update 4, 532-538.

Liu, K. E., Hartman, M., Hartman, A., Luo, Z. C., and Mahutte, N. (2018). The impact of a thin endometrial lining on fresh and frozen-thaw IVF outcomes: an analysis of over 40000 embryo transfers. Hum. Reprod. 33, 1883-1888. doi: 10.1093/humrep/dey281

Lopata, A., and Hay, D. L. (1989). The potential of early human embryos to form blastocysts, hatch from their zona and secrete HCG in culture. Hum. Reprod. 4(8 Suppl.), 87-94.

Mackens, S., Racca, A., Van de Velde, H., Drakopoulos, P., Tournaye, H., Stoop, D., et al. (2020). Follicular-phase endometrial scratching: a truncated randomized controlled trial. Hum. Reprod. 35, 1090-1098. doi: 10.1093/humrep/deaa018

Madkour, A., Bouamoud, N., Louanjli, N., Kaarouch, I., Copin, H., Benkhalifa, M., et al. (2016). Intrauterine insemination of cultured peripheral blood mononuclear cells prior to embryo transfer improves clinical outcome for patients with repeated implantation failures. Zygote 24, 58-69. doi: 10.1017/ s0967199414000719

Makker, A., Goel, M. M., Nigam, D., Bhatia, V., Mahdi, A. A., Das, V., et al. (2017). Endometrial Expression of Homeobox Genes and Cell Adhesion Molecules in Infertile Women With Intramural Fibroids During Window of Implantation. Reprod. Sci. 24, 435-444. doi: 10.1177/1933719116657196

Makrigiannakis, A., BenKhalifa, M., Vrekoussis, T., Mahjub, S., Kalantaridou, S. N., and Gurgan, T. (2015). Repeated implantation failure: a new potential treatment option. Eur. J. Clin. Invest. 45, 380-384. doi: 10.1111/eci.12417

Makrigiannakis, A., Vrekoussis, T., Makrygiannakis, F., Ruso, H., Kalantaridou, S. N., and Gurgan, T. (2019). Intrauterine CRH-treated PBMC in repeated implantation failure. Eur. J. Clin. Invest. 49:e13084. doi: 10.1111/eci.13084

Maleki-Hajiagha, A., Razavi, M., Rezaeinejad, M., Rouholamin, S., AlmasiHashiani, A., Pirjani, R., et al. (2019). Intrauterine administration of autologous peripheral blood mononuclear cells in patients with recurrent implantation failure: A systematic review and meta-analysis. J Reprod. Immunol. 131, 50-56. doi: 10.1016/j.jri.2019.01.001

Maleki-Hajiagha, A., Razavi, M., Rouholamin, S., Rezaeinejad, M., Maroufizadeh, S., and Sepidarkish, M. (2020). Intrauterine infusion of autologous platelet-rich plasma in women undergoing assisted reproduction: A systematic review and meta-analysis. J. Reprod. Immunol. 137:103078. doi: 10.1016/j.jri.2019.103078

Mansour, R., Tawab, N., Kamal, O., El-Faissal, Y., Serour, A., Aboulghar, M., et al. (2011). Intrauterine injection of human chorionic gonadotropin before embryo transfer significantly improves the implantation and pregnancy rates in in vitro fertilization/intracytoplasmic sperm injection: a prospective randomized study. Fertil. Steril. 96, 1370.e-1374.e. doi: 10.1016/j.fertnstert.2011.09.044

Mao, X., Wu, L., Chen, Q., Kuang, Y., and Zhang, S. (2019). Effect of hysteroscopy before starting in-vitro fertilization for women with recurrent implantation failure: A meta-analysis and systematic review. Medicine 98:e14075. doi: 10. 1097/md.0000000000014075

Miwa, I., Tamura, H., Takasaki, A., Yamagata, Y., Shimamura, K., and Sugino, N. (2009). Pathophysiologic features of "thin" endometrium. Fertil. Steril. 91, 998-1004. doi: 10.1016/j.fertnstert.2008.01.029

Moldenhauer, L. M., Keenihan, S. N., Hayball, J. D., and Robertson, S. A. (2010). GM-CSF is an essential regulator of $\mathrm{T}$ cell activation competence in uterine dendritic cells during early pregnancy in mice. J. Immunol. 185, 7085-7096. doi: 10.4049/jimmunol.1001374

Molina, N. M., Sola-Leyva, A., Saez-Lara, M. J., Plaza-Diaz, J., Tubić-Pavlović, A., Romero, B., et al. (2020). New Opportunities for Endometrial Health by Modifying Uterine Microbial Composition: Present or Future? Biomolecules 10:10040593. doi: 10.3390/biom10040593

Mor, G., Cardenas, I., Abrahams, V., and Guller, S. (2011). Inflammation and pregnancy: the role of the immune system at the implantation site. Ann. N Y. Acad. Sci. 1221, 80-87. doi: 10.1111/j.1749-6632.2010. 05938.x 
Mor, G., and Kwon, J. Y. (2015). Trophoblast-microbiome interaction: a new paradigm on immune regulation. Am. J. Obstet. Gynecol. 213(4 Suppl.), S131S137. doi: 10.1016/j.ajog.2015.06.039

Moraloglu, O., Tonguc, E., Var, T., Zeyrek, T., and Batioglu, S. (2010). Treatment with oxytocin antagonists before embryo transfer may increase implantation rates after IVF. Reprod. Biomed. Online 21, 338-343. doi: 10.1016/j.rbmo.2010. 04.009

Moreno, I., Codoñer, F. M., Vilella, F., Valbuena, D., Martinez-Blanch, J. F., Jimenez-Almazán, J., et al. (2016). Evidence that the endometrial microbiota has an effect on implantation success or failure. Am. J. Obstet. Gynecol. 215, 684-703. doi: 10.1016/j.ajog.2016.09.075

Mostajeran, F., Godazandeh, F., Ahmadi, S. M., Movahedi, M., and Jabalamelian, S. A. (2017). Effect of intrauterine injection of human chorionic gonadotropin before embryo transfer on pregnancy rate: A prospective randomized study. Arch. Gynecol. Obstet. 22:6. doi: 10.4103/1735-1995.199096

Nakayama, T., Fujiwara, H., Maeda, M., Inoue, T., Yoshioka, S., Mori, T., et al. (2002). Human peripheral blood mononuclear cells (PBMC) in early pregnancy promote embryo invasion in vitro: HCG enhances the effects of PBMC. Hum. Reprod. 17, 207-212. doi: 10.1093/humrep/17.1.207

Nastri, C. O., Gibreel, A., Raine-Fenning, N., Maheshwari, A., Ferriani, R. A., Bhattacharya, S., et al. (2012). Endometrial injury in women undergoing assisted reproductive techniques. Cochrane Database Syst. Rev. 2012:Cd009517. doi: 10.1002/14651858.CD009517.pub2

Navali, N., Gassemzadeh, A., Farzadi, L., Abdollahi, S., Nouri, M., Hamdi, K., et al. (2016). Intrauterine administration of hCG immediately after oocyte retrieval and the outcome of ICSI: a randomized controlled trial. Hum. Reprod. 31, 2520-2526. doi: 10.1093/humrep/dew236

Nazari, L., Salehpour, S., Hosseini, M. S., and Hashemi Moghanjoughi, P. (2020). The effects of autologous platelet-rich plasma in repeated implantation failure: a randomized controlled trial. Hum. Fertil. 23, 209-213. doi: 10.1080/14647273. 2019.1569268

Ng, E. H., Li, R. H., Chen, L., Lan, V. T., Tuong, H. M., and Quan, S. (2014). A randomized double blind comparison of atosiban in patients undergoing IVF treatment. Hum. Reprod. 29, 2687-2694. doi: 10.1093/humrep/deu263

Nobijari, F. F., Arefi, S. S., Moini, A., Taheripanah, R., Fazeli, E., Kharazi, H., et al. (2019). Endometrium immunomodulation by intrauterine insemination administration of treated peripheral blood mononuclear cell prior frozen/thawed embryos in patients with repeated implantation failure. Zygote 27, 214-218. doi: 10.1017/s0967199419000145

Okitsu, O., Kiyokawa, M., Oda, T., Miyake, K., Sato, Y., and Fujiwara, H. (2011). Intrauterine administration of autologous peripheral blood mononuclear cells increases clinical pregnancy rates in frozen/thawed embryo transfer cycles of patients with repeated implantation failure. J. Reprod. Immunol. 92, 82-87. doi: 10.1016/j.jri.2011.07.001

Osman, A., Pundir, J., Elsherbini, M., Dave, S., El-Toukhy, T., and Khalaf, Y. (2016). The effect of intrauterine HCG injection on IVF outcome: a systematic review and meta-analysis. Reprod. Biomed. Online 33, 350-359. doi: 10.1016/j.rbmo. 2016.05.010

Panagiotopoulou, N., Karavolos, S., and Choudhary, M. (2015). Endometrial injury prior to assisted reproductive techniques for recurrent implantation failure: a systematic literature review. Eur. J. Obstet. Gynecol. Reprod. Biol. 193, 27-33. doi: 10.1016/j.ejogrb.2015.06.026

Pier, B., Crellin, C., Katre, A., Conner, M. G., Novak, L., Young, S. L., et al. (2020). Large, Non-Cavity Distorting Intramural Leiomyomas Decrease Leukemia Inhibitory Factor in the Secretory Phase Endometrium. Reprod. Sci. 27, 569574. doi: 10.1007/s43032-019-00056-x

Pierzynski, P., Reinheimer, T. M., and Kuczynski, W. (2007). Oxytocin antagonists may improve infertility treatment. Fertil. Steril. 88, 219-222e. doi: 10.1016/j. fertnstert.2006.09.017

Potdar, N., Gelbaya, T., and Nardo, L. G. (2012). Endometrial injury to overcome recurrent embryo implantation failure: a systematic review and meta-analysis. Reprod. Biomed. Online 25, 561-571. doi: 10.1016/j.rbmo.2012.08.005

Pourmoghadam, Z., Abdolmohammadi-Vahid, S., Pashazadeh, F., AghebatiMaleki, L., Ansari, F., and Yousefi, M. (2020a). Efficacy of intrauterine administration of autologous peripheral blood mononuclear cells on the pregnancy outcomes in patients with recurrent implantation failure: A systematic review and meta-analysis. J. Reprod. Immunol. 137:103077. doi: 10. 1016/j.jri.2019.103077
Pourmoghadam, Z., Soltani-Zangbar, M. S., Sheikhansari, G., Azizi, R., EghbalFard, S., Mohammadi, H., et al. (2020b). Intrauterine administration of autologous hCG- activated peripheral blood mononuclear cells improves pregnancy outcomes in patients with recurrent implantation failure; A doubleblind, randomized control trial study. J. Reprod. Immunol. 142:103182. doi: 10.1016/j.jri.2020.103182

Quaas, A., and Dokras, A. (2008). Diagnosis and treatment of unexplained infertility. Rev. Obstet. Gynecol. 1, 69-76.

Ravel, J., Gajer, P., Abdo, Z., Schneider, G. M., Koenig, S. S., McCulle, S. L., et al. (2011). Vaginal microbiome of reproductive-age women. Proc. Natl. Acad. Sci. U S A. 108 Suppl 1(Suppl. 1), 4680-4687. doi: 10.1073/pnas.1002611107

Rikhraj, K., Tan, J., Taskin, O., Albert, A. Y., Yong, P., and Bedaiwy, M. A. (2020). The Impact of Noncavity-Distorting Intramural Fibroids on Live Birth Rate in In Vitro Fertilization Cycles: A Systematic Review and Meta-Analysis. J. Womens Health 29, 210-219. doi: 10.1089/jwh.2019.7813

Robert, C. A., Abbas, M. K., Zaidi, A. R. Z., Thiha, S., and Malik, B. H. (2019). Mediator in the Embryo-endometrium Cross-talk: Granulocyte Colonystimulating Factor in Infertility. Cureus 11:e5390. doi: 10.7759/cureus.5390

RoyChoudhury, S., Singh, A., Gupta, N. J., Srivastava, S., Joshi, M. V., Chakravarty, B., et al. (2016). Repeated implantation failure versus repeated implantation success: discrimination at a metabolomic level. Hum. Reprod. 31, 1265-1274. doi: 10.1093/humrep/dew064

Salter, S. J., Cox, M. J., Turek, E. M., Calus, S. T., Cookson, W. O., Moffatt, M. F., et al. (2014). Reagent and laboratory contamination can critically impact sequence-based microbiome analyses. BMC Biol. 12:87. doi: 10.1186/s12915014-0087-z

Santibañez, A., García, J., Pashkova, O., Colín, O., Castellanos, G., Sánchez, A. P., et al. (2014). Effect of intrauterine injection of human chorionic gonadotropin before embryo transfer on clinical pregnancy rates from in vitro fertilisation cycles: a prospective study. Reprod. Biol. Endocrinol. 12:9. doi: 10.1186/14777827-12-9

Santillán, I., Lozano, I., Illán, J., Verdú, V., Coca, S., Bajo-Arenas, J. M., et al. (2015). Where and when should natural killer cells be tested in women with repeated implantation failure? J. Reprod. Immunol. 108, 142-148. doi: 10.1016/j.jri.2014. 12.009

Sar-Shalom Nahshon, C., Sagi-Dain, L., Wiener-Megnazi, Z., and Dirnfeld, M. (2019). The impact of intentional endometrial injury on reproductive outcomes: a systematic review and meta-analysis. Hum. Reprod. Update 25, 95-113. doi: 10.1093/humupd/dmy034

Sarvi, F., Arabahmadi, M., Alleyassin, A., Aghahosseini, M., and Ghasemi, M. (2017). Effect of Increased Endometrial Thickness and Implantation Rate by Granulocyte Colony-Stimulating Factor on Unresponsive Thin Endometrium in Fresh In Vitro Fertilization Cycles: A Randomized Clinical Trial. Obstet. Gynecol. Int. 2017:3596079. doi: 10.1155/2017/3596079

Sbracia, M., Scarpellini, F., Poverini, R., Alò, P. L., Rossi, G., and Di Tondo, U. (2004). Immunohistochemical localization of the growth hormone in human endometrium and decidua. Am. J. Reprod. Immunol. 51, 112-116. doi: 10.1046/ j.8755-8920.2003.00127.x

Schumacher, A., Brachwitz, N., Sohr, S., Engeland, K., Langwisch, S., Dolaptchieva, M., et al. (2009). Human chorionic gonadotropin attracts regulatory T cells into the fetal-maternal interface during early human pregnancy. J. Immunol. 182, 5488-5497. doi: 10.4049/jimmunol.0803177

Seshadri, S., and Sunkara, S. K. (2014). Natural killer cells in female infertility and recurrent miscarriage: a systematic review and meta-analysis. Hum. Reprod. Update 20, 429-438. doi: 10.1093/humupd/dmt056

Sharma, R., and Das, A. (2014). Organ-specific phenotypic and functional features of NK cells in humans. Immunol. Res. 58, 125-131. doi: 10.1007/s12026-0138477-9

Shi, C., Shen, H., Fan, L. J., Guan, J., Zheng, X. B., Chen, X., et al. (2017). Endometrial MicroRNA Signature during the Window of Implantation Changed in Patients with Repeated Implantation Failure. Chin. Med. J. 130, 566-573. doi: 10.4103/0366-6999.200550

Simón, C., and Bellver, J. (2014). Scratching beneath 'The Scratching Case': systematic reviews and meta-analyses, the back door for evidence-based medicine. Hum. Reprod. 29, 1618-1621. doi: 10.1093/humrep/deu126

Stanhiser, J., and Steiner, A. Z. (2018). Psychosocial Aspects of Fertility and Assisted Reproductive Technology. Obstet. Gynecol. Clin. North Am. 45, 563-574. doi: 10.1016/j.ogc.2018.04.006 
Tapia-Pizarro, A., Archiles, S., Argandona, F., Valencia, C., Zavaleta, K., Cecilia Johnson, M., et al. (2017). hCG activates Epac-Erk1/2 signaling regulating Progesterone Receptor expression and function in human endometrial stromal cells. Mol. Hum. Reprod. 23, 393-405. doi: 10.1093/molehr/gax015

Tapia-Pizarro, A., Argandona, F., Palomino, W. A., and Devoto, L. (2013). Human chorionic gonadotropin (hCG) modulation of TIMP1 secretion by human endometrial stromal cells facilitates extravillous trophoblast invasion in vitro. Hum. Reprod. 28, 2215-2227. doi: 10.1093/humrep/det136

Tersoglio, A. E., Salatino, D. R., Reinchisi, G., Gonzalez, A., Tersoglio, S., and Marlia, C. (2015). Repeated implantation failure in oocyte donation. What to do to improve the endometrial receptivity? JBRA Assist. Reprod. 19, 44-52. doi: 10.5935/1518-0557.20150012

Toth, B., Roth, K., Kunert-Keil, C., Scholz, C., Schulze, S., Mylonas, I., et al. (2008). Glycodelin protein and mRNA is downregulated in human first trimester abortion and partially upregulated in mole pregnancy. J. Histochem. Cytochem. 56, 477-485. doi: 10.1369/jhc.2008.950600

van Hoogenhuijze, N. E., Kasius, J. C., Broekmans, F. J. M., Bosteels, J., and Torrance, H. L. (2019). Endometrial scratching prior to IVF; does it help and for whom? A systematic review and meta-analysis. Hum. Reprod. Open 2019:hoy025. doi: 10.1093/hropen/hoy025

VanderWeele, T. J., and Knol, M. J. (2011). Interpretation of subgroup analyses in randomized trials: heterogeneity versus secondary interventions. Ann. Intern. Med. 154, 680-683. doi: 10.7326/0003-4819-154-10-201105170-00008

Vento-Tormo, R., Efremova, M., Botting, R. A., Turco, M. Y., Vento-Tormo, M., Meyer, K. B., et al. (2018). Single-cell reconstruction of the early maternal-fetal interface in humans. Nature 563, 347-353. doi: 10.1038/s41586-018-0698-6

Vitagliano, A., Andrisani, A., Alviggi, C., Vitale, S. G., Valenti, G., Sapia, F., et al. (2019). Endometrial scratching for infertile women undergoing a first embryo transfer: a systematic review and meta-analysis of published and unpublished data from randomized controlled trials. Fertil. Steril. 111:734.e-746.e. doi: 10. 1016/j.fertnstert.2018.12.008

Vitagliano, A., Di Spiezio, Sardo, A., Saccone, G., Valenti, G., Sapia, F., et al. (2018a). Endometrial scratch injury for women with one or more previous failed embryo transfers: a systematic review and meta-analysis of randomized controlled trials. Fertil. Steril. 110, 687.e-702.e. doi: 10.1016/j.fertnstert.2018.04.040

Vitagliano, A., Saccardi, C., Noventa, M., Di Spiezio, Sardo, A., Saccone, G., et al. (2018b). Effects of chronic endometritis therapy on in vitro fertilization outcome in women with repeated implantation failure: a systematic review and meta-analysis. Fertil. Steril. 110, 103.e-112.e. doi: 10.1016/j.fertnstert.2018.03. 017

Volodarsky-Perel, A., Buckett, W., and Tulandi, T. (2019). Treatment of hydrosalpinx in relation to IVF outcome: a systematic review and meta-analysis. Reprod. Biomed. Online 39, 413-432. doi: 10.1016/j.rbmo.2019.04.012

Volovsky, M., Healey, M., MacLachlan, V., and Vollenhoven, B. J. (2018). Should intrauterine human chorionic gonadotropin infusions ever be used prior to embryo transfer? J. Assist. Reprod. Genet. 35, 273-278. doi: 10.1007/s10815-0171049-5

Wang, X., Chen, L., Wang, H., Li, Q., Liu, X., and Qi, H. (2018). The Impact of Noncavity-Distorting Intramural Fibroids on the Efficacy of In Vitro Fertilization-Embryo Transfer: An Updated Meta-Analysis. Biomed. Res. Int. 2018:8924703. doi: 10.1155/2018/8924703

Wang, Y., Yao, Z., Zhao, H., Yue, C., Yu, Q., Zhang, Y., et al. (2020). Reproductive outcomes of in vitro fertilization-intracytoplasmic sperm injection after transcervical resection of adhesions: a retrospective cohort study. J. Minim. Invasive Gynecol. 2020:29. doi: 10.1016/j.jmig.2020.10.029

Weyrich, L. S., Farrer, A. G., Eisenhofer, R., Arriola, L. A., Young, J., Selway, C. A., et al. (2019). Laboratory contamination over time during low-biomass sample analysis. Mol. Ecol. Resour. 19, 982-996. doi: 10.1111/1755-0998.13011

Wirleitner, B., Schuff, M., Vanderzwalmen, P., Stecher, A., Okhowat, J., Hradecký, L., et al. (2015). Intrauterine administration of human chorionic gonadotropin does not improve pregnancy and life birth rates independently of blastocyst quality: a randomised prospective study. Reprod. Biol. Endocrinol. 13:70. doi: 10.1186/s12958-015-0069-1

Woon, E. V., Day, A., Bracewell-Milnes, T., Male, V., and Johnson, M. (2020). Immunotherapy to improve pregnancy outcome in women with abnormal natural killer cell levels/activity and recurrent miscarriage or implantation failure: A systematic review and meta-analysis. J. Reprod. Immunol. 142:103189. doi: 10.1016/j.jri.2020.103189
Wu, F., Chen, X., Liu, Y., Liang, B., Xu, H., Li, T. C., et al. (2018). Decreased MUC1 in endometrium is an independent receptivity marker in recurrent implantation failure during implantation window. Reprod. Biol. Endocrinol. 16:60. doi: 10.1186/s12958-018-0379-1

Wu, M. H., Lin, C. W., Su, P. F., Lai, E. C., Sie, F. C., Mau, Y. L., et al. (2020). Atosiban and Pregnancy Outcomes Following In Vitro Fertilization Treatment for Infertile Women Requiring One, Two, or More Embryo Transfer Cycles: A Longitudinal Cohort Study. Reprod. Sci. 27, 853-859. doi: 10.1007/s43032-01900088-3

Xie, H., Zeng, H., He, D., and Liu, N. (2019). Effect of intrauterine perfusion of human chorionic gonadotropin before embryo transfer after two or more implantation failures: A systematic review and meta-analysis. Eur. J. Obstet. Gynecol. Reprod. Biol. 243, 133-138. doi: 10.1016/j.ejogrb.2019.10.039

Xu, Y., Mei, J., Diao, L., Li, Y., and Ding, L. (2020). Chronic endometritis and reproductive failure: Role of syndecan-1. Am. J. Reprod. Immunol. 84:e13255. doi: 10.1111/aji.13255

Yakin, K., Oktem, O., and Urman, B. (2019). Intrauterine administration of peripheral mononuclear cells in recurrent implantation failure: a systematic review and meta-analysis. Sci. Rep. 9:3897. doi: 10.1038/s41598-01940521-w

Yamada, H., Morikawa, M., Kato, E. H., Shimada, S., Kobashi, G., and Minakami, H. (2003). Pre-conceptional natural killer cell activity and percentage as predictors of biochemical pregnancy and spontaneous abortion with normal chromosome karyotype. Am. J. Reprod. Immunol. 50, 351-354. doi: 10.1034/j. 1600-0897.2003.00095.x

Yang, D. N., Wu, J. H., Geng, L., Cao, L. J., Zhang, Q. J., Luo, J. Q., et al. (2020). Efficacy of intrauterine perfusion of peripheral blood mononuclear cells (PBMC) for infertile women before embryo transfer: meta-analysis. J. Obstet. Gynaecol. 40, 961-968. doi: 10.1080/01443615.2019.1673711

Yang, H., Lei, C. X., and Zhang, W. (2013). Human chorionic gonadotropin (hCG) regulation of galectin-3 expression in endometrial epithelial cells and endometrial stromal cells. Acta Histochem. 115, 3-7. doi: 10.1016/j.acthis.2011. 05.002

Yang, J. H., Chen, C. D., Chou, C. H., Wen, W. F., Tsao, P. N., Lee, H., et al. (2019). Intentional endometrial injury increases embryo implantation potentials through enhanced endometrial angiogenesist. Biol. Reprod. 100, 381-389. doi: 10.1093/biolre/ioy205

Yang, R., Du, X., Wang, Y., Song, X., Yang, Y., and Qiao, J. (2014). The hysteroscopy and histological diagnosis and treatment value of chronic endometritis in recurrent implantation failure patients. Arch. Gynecol. Obstet. 289, 1363-1369. doi: 10.1007/s00404-013-3131-2

Ye, H., Hu, J., He, W., Zhang, Y., and Li, C. (2015). The efficacy of intrauterine injection of human chorionic gonadotropin before embryo transfer in assisted reproductive cycles: Meta-analysis. J. Int. Med. Res. 43, 738-746. doi: 10.1177/ 0300060515592903

Yeung, T. W., Chai, J., Li, R. H., Lee, V. C., Ho, P. C., and Ng, E. H. (2014). The effect of endometrial injury on ongoing pregnancy rate in unselected subfertile women undergoing in vitro fertilization: a randomized controlled trial. Hum. Reprod. 29, 2474-2481. doi: 10.1093/humrep/deu213

Yoshioka, S., Fujiwara, H., Nakayama, T., Kosaka, K., Mori, T., and Fujii, S. (2006). Intrauterine administration of autologous peripheral blood mononuclear cells promotes implantation rates in patients with repeated failure of IVF-embryo transfer. Hum. Reprod. 21, 3290-3294. doi: 10.1093/humrep/del312

Yu, N., Zhang, B., Xu, M., Wang, S., Liu, R., Wu, J., et al. (2016). Intrauterine administration of autologous peripheral blood mononuclear cells (PBMCs) activated by HCG improves the implantation and pregnancy rates in patients with repeated implantation failure: a prospective randomized study. Am. J. Reprod. Immunol. 76, 212-216. doi: 10.1111/aji.12542

Yu, X., Gao, C., Dai, C., Yang, F., and Deng, X. (2019). Endometrial injury increases expression of hypoxia-inducible factor and angiogenesis in the endometrium of women with recurrent implantation failure. Reprod. Biomed. Online 38, 761-767. doi: 10.1016/j.rbmo.2018.12.027

Yuan, C., Song, H., Fan, L., Su, S., and Dong, B. (2019). The Effect of Atosiban on Patients With Difficult Embryo Transfers Undergoing In Vitro FertilizationEmbryo Transfer. Reprod. Sci. 26, 1613-1617. doi: 10.1177/193371911983 1791

Zamaniyan, M., Peyvandi, S., Heidaryan Gorji, H., Moradi, S., Jamal, J., Yahya Poor, et al. (2020). Effect of platelet-rich plasma on pregnancy outcomes in 
infertile women with recurrent implantation failure: a randomized controlled trial. Gynecol. Endocrinol. 2020, 1-5. doi: 10.1080/09513590.2020.1756247

Zarei, A., Parsanezhad, M. E., Younesi, M., Alborzi, S., Zolghadri, J., Samsami, A., et al. (2014). Intrauterine administration of recombinant human chorionic gonadotropin before embryo transfer on outcome of in vitro fertilization/ intracytoplasmic sperm injection: A randomized clinical trial. Iran J. Reprod. Med. 12, 1-6.

Zhang, H., Huang, C., Chen, X., Li, L., Liu, S., Li, Y., et al. (2020). The number and cytotoxicity and the expression of cytotoxicity-related molecules in peripheral natural killer (NK) cells do not predict the repeated implantation failure (RIF) for the in vitro fertilization patients. Genes Dis. 7, 283-289. doi: 10.1016/j. gendis.2019.03.005

Zhang, Y., Xu, H., Liu, Y., Zheng, S., Zhao, W., Wu, D., et al. (2019). Confirmation of chronic endometritis in repeated implantation failure and success outcome in IVF-ET after intrauterine delivery of the combined administration of antibiotic and dexamethasone. Am. J. Reprod. Immunol. 82:e13177. doi: 10.1111/aji. 13177
Zhao, J., Xu, B., Xie, S., Zhang, Q., and Li, Y. P. (2016). Whether G-CSF administration has beneficial effect on the outcome after assisted reproductive technology? A systematic review and metaanalysis. Reprod. Biol. Endocrinol. 14:62. doi: 10.1186/s12958-016$0197-2$

Conflict of Interest: The authors declare that the research was conducted in the absence of any commercial or financial relationships that could be construed as a potential conflict of interest.

Copyright $(2021$ Makrigiannakis, Makrygiannakis and Vrekoussis. This is an openaccess article distributed under the terms of the Creative Commons Attribution License (CC BY). The use, distribution or reproduction in other forums is permitted, provided the original author(s) and the copyright owner(s) are credited and that the original publication in this journal is cited, in accordance with accepted academic practice. No use, distribution or reproduction is permitted which does not comply with these terms. 